\title{
Improved direct diabatization and coupled potential energy surfaces for the photodissociation of ammonia
}

\author{
Zhen Hua Li · Rosendo Valero • Donald G. Truhlar
}

Received: 3 October 2006 / Accepted: 9 November 2006 / Published online: 6 March 2007

(C) Springer-Verlag 2007

\begin{abstract}
Diabatic potential energy surfaces are a convenient starting point for dynamics calculations of photochemical processes, and they can be calculated by the fourfold way direct diabatization scheme. Here we present an improved definition of the reference orbital for applying the fourfold way direct diabatization scheme to ammonia. The improved reference orbital is a geometry-dependent hybrid orbital that allows one to define consistent dominant configuration lists at all geometries important for photodissociation. Using diabatic energies calculated with the new reference orbital and consistent dominant configuration lists, we have refitted the analytical representations of the ground and the first electronically excited singlet-state potential energy surfaces and the diabatic coupling surface. Improved functional forms were used to reproduce the experimental dissociation energies and excitation energies, which will be important for subsequent simulations of photochemical dynamics. We find that the lowestenergy conical intersection point is at $5.16 \mathrm{eV}$, with $C_{2 \mathrm{v}}$ symmetry.
\end{abstract}

Electronic supplementary material The online version of this article (doi:10.1007/s00214-006-0237-7) contains supplementary material, which is available to authorized users.

This article is part of the special issue dedicated to the memory of the late Professor Fernando Bernardi.

Z. H. Li · R. Valero · D. G. Truhlar $(\bowtie)$

Department of Chemistry and Supercomputing Institute, University of Minnesota, Minneapolis, MN 55455-0431, USA

e-mail: truhlar@umn.edu

\section{Introduction}

Nangia and one of the authors [1] have recently used the fourfold way direct diabatization scheme [2-4] to generate coupled potential energy surfaces (PESs) for the photodissociation of ammonia. This involved using the threefold density criterion and a reference orbital on nitrogen to generate diabatic molecular orbitals (DMOs), specification of diabatic prototypes in terms of lists of dominant configuration state functions (CSFs) defined in terms of the DMOs, and transformation of adiabatic many-electron state functions to diabatic state functions by the principle of configurational uniformity [2-6]. The diabatic surfaces and couplings were calculated at 3,600 geometries, fitted to economical analytic functions incorporating the full permutational symmetry of the three hydrogen atoms, and used to explore the four-dimensional conical intersection seams.

In subsequent unpublished work we attempted to employ this analytic potential energy matrix for semiclassical trajectory calculations, and this attempt showed that the surfaces had unrealistic values in certain regions of configuration space that were apparently not well enough represented in our data set (regions with partly dissociated bonds where the sets of bond angles were in certain ranges and also in certain high-energy regions where the ammonia umbrella is very closed). In the process of generating more data for a wider range of geometries, we discovered that we needed to develop a more robust definition of the reference orbital and a better fitting function to achieve a smooth global potential energy matrix with more accurate asymptotic behavior. Along the way we also developed improved dominant configuration lists for the diabatic states. We used the improved reference orbital and dominant configuration 
lists to generate diabatic surfaces and their couplings at 8,227 geometries spanning a broader range than in the previous work, and we fitted these surfaces to the new functional forms. We then tested the resulting potentials in sample semiclassical trajectory calculations to ensure that the nonphysical energies were properly corrected.

In the present article we report these new, more robust procedures and the resulting potential energy surfaces and couplings. A dynamical study employing these new surfaces is in progress.

\section{Theory and calculations}

We will repeat as little as possible of the theory [2-4] and the details of the previous [1] application to $\mathrm{NH}_{3}$. The MC-QDPT method [7-9] with a state-averaged CASSCF reference function $[10,11]$ was used in all the calculations that were used for diabatization. The $1 \mathrm{~s}$ core orbital of nitrogen was kept frozen (that is, kept doubly occupied in all CSFs) in the MC-QDPT step, which includes all the double excitations from the active orbitals through second order. To avoid artifacts due to intruder states in the MC-QDPT wave function, the intruder state avoidance (ISA) method [12] was used in all the calculations. The level shift parameter [12] $b$ of the ISA method was set to $0.02 E_{\mathrm{h}}^{2}$ (note: $1 E_{\mathrm{h}} \equiv 1$ hartree). The CASSCF wave function was obtained as a state average with equal weights for the lowest two adiabatic singlet electronic states of $\mathrm{NH}_{3}$. The active space contains eight electrons in seven orbitals, which is sometimes denoted $(8,7)$. We used the $6-311++\mathrm{G}(3 \mathrm{df}, 3 \mathrm{pd})$ $[13,14]$ basis set with six sets of six Cartesian $d$ functions (three on $\mathrm{N}$, one on each $\mathrm{H}$ ) and one set of ten Cartesian $f$ functions (on $\mathrm{N}$ ).

The seven active orbitals were chosen as follows. First, we include in the active space the four occupied molecular orbitals (MOs) of the reference restricted HartreeFock (RHF) wave function, which are three bonding $\mathrm{N}-\mathrm{H}$ MOs and one nonbonding orbital centered on the nitrogen atom. Then we include three virtual orbitals of the RHF wave function, in particular two antibonding $\mathrm{N}-\mathrm{H}$ MOs and one Rydberg-type MO with $3 s$ character centered on the nitrogen atom at short $\mathrm{N}-\mathrm{H}$ distances. The Rydberg MO transforms into a $1 s$ atomic orbital centered on the dissociating hydrogen atom at long $\mathrm{N}-\mathrm{H}$ distances.

The electronic structure calculations used to generate the PESs were carried out with HONDOPLUS v. 5.1 $[15,16]$. The ISA algorithm was added to HONDOPLUS from the version in GAMESS [17].

Additional state-specific CASSCF calculations with the same active space and basis set were carried out for the minima of the ground and excited state $\mathrm{PESs}$ of $\mathrm{NH}_{3}$ as well as for the $\mathrm{NH}_{2}+\mathrm{H}$ dissociation limit with the $\mathrm{NH}_{2}$ fragment in its ground and first excited electronic states. These calculations employed Gaussian 03 [18].

In order to establish the list of CSFs defining the diabatic prototypes of the fourfold way, first the diabatic MOs (DMOs) obtained by the threefold way at planar and nonplanar geometries and at short and long $\mathrm{N}-\mathrm{A}$ distances (the dissociating hydrogen atom is denoted as $\mathrm{H}_{\mathrm{A}}$ or $\mathrm{A}$, depending on the context, and the other hydrogens are $\mathrm{H}_{\mathrm{B}}$ and $\mathrm{H}_{\mathrm{C}}$ or $\mathrm{B}$ and $\mathrm{C}$ ) were correlated. It is only necessary to consider dissociation of one of the hydrogen atoms, since the two other possible N-H dissociations can be obtained by symmetry. The correlations are shown in Table 1 . In this table, the $\mathrm{NH}_{3}$ moiety is assumed to be oriented with the nitrogen atom at the origin and the two hydrogen atoms that do not dissociate situated in the $x y$ plane. For planar geometries the dissociating hydrogen atom is also situated in the $x y$ plane. A particular set of nonplanar geometries is defined such that the dissociating hydrogen atom is directed along the $z$-axis. Although for a general nonplanar geometry the dissociating hydrogen atom can point in an arbitrary direction, this particular orientation of the dissociating hydrogen atom has been chosen to illustrate the problems encountered when one tries to define diabatic prototypes consistently for both planar and nonpla-

Table 1 Correlation of DMOs between the different $\mathrm{NH}_{3}$ geometries by the threefold way

\begin{tabular}{llll}
\hline$\beta(\mathrm{deg})^{\mathrm{a}}$ & Small N-A distance $\left(\mathrm{NH}_{3}\right)$ & Intermediate $\mathrm{N}-\mathrm{A}$ distance $\left(\mathrm{NH}_{3}\right)$ & Large $\mathrm{N}-\mathrm{A}$ distance $(\mathrm{NH} 2+\mathrm{H})$ \\
\hline$\beta=90^{\mathrm{b}}$ & $\sigma_{\mathrm{N}-\mathrm{A}} p_{z} R$ & $\sigma_{\mathrm{N}-\mathrm{A}} p_{z} R$ & $s p^{2} p_{z} h$ \\
$75<\beta<90^{\mathrm{c}}$ & $\sigma_{\mathrm{N}-\mathrm{A}} n R$ & $\sigma_{\mathrm{N}-\mathrm{A}} n R$ & $s p^{2} p_{z} h$ \\
$\beta<75^{c}$ & $\sigma_{\mathrm{N}-\mathrm{A}} n R$ & $n \sigma_{\mathrm{N}-\mathrm{A}} R$ & $s p^{2} p_{z} h$ \\
\hline
\end{tabular}

Each entry is an ordered list of three diabatic molecular orbitals; in comparing entries, the first orbital of one entry correlated with the first of another, the second with the second, and the third with the third. For small and intermediate $\mathrm{N}-\mathrm{A}$, the $z$ direction is perpendicular to the NBC plane, $s p^{2}$ denotes an in-plane nonbonding orbital of $\mathrm{NH}_{2}$, where "plane" refers to the NBC plane, $h$ denotes an orbital localized on the dissociated hydrogen, and $\sigma_{\mathrm{N}-\mathrm{A}}$ is a bonding orbital

${ }^{a} \beta$ is the angle between an $\mathrm{N}-\mathrm{H}$ bond axis and the trisector of all the $\mathrm{N}-\mathrm{H}$ bond axes (see Fig. 2)

b Planar

c Nonplanar 


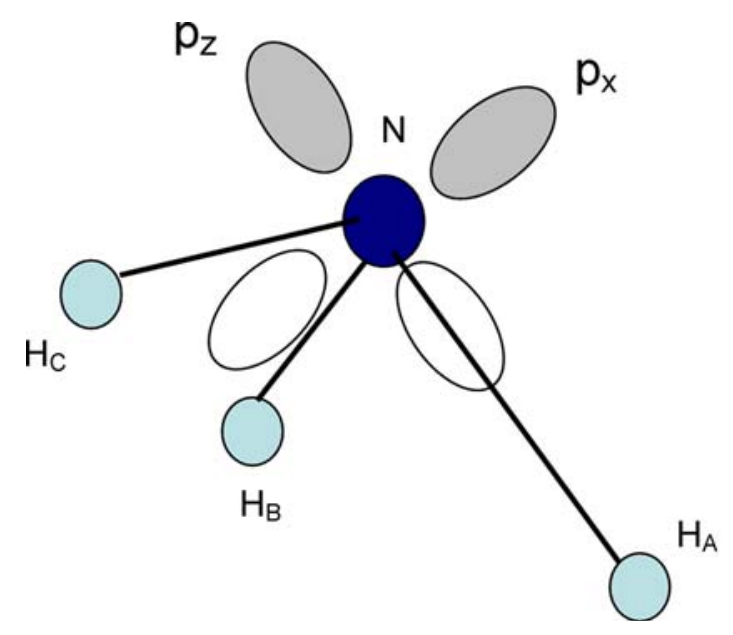

Fig. 1 Pictorial representation of the $\mathrm{NH}_{3}$ system with $p_{x}$ - and $p_{z}$-type DMOs which mix as the $\mathrm{N}-\mathrm{A}$ distance and the trisector angle change. See text for a detailed explanation

nar geometries by applying the overlap criterion to the DMOs obtained by the threefold way.

In Table 1 , for small $\mathrm{N}-\mathrm{A}$ distances, " $\sigma_{\mathrm{N}-\mathrm{A}}$ " denotes a bonding DMO between the nitrogen atom and the dissociating hydrogen atom, " $p_{z}$ " is a nonbonding $p$-type orbital centered on the nitrogen atom, " $R$ " is a Rydberg-type $3 s$ orbital centered on the nitrogen atom, and " $n$ " is a nonbonding orbital centered on the nitrogen atom, but not oriented in a particular direction for nonplanar geometries. Likewise, for large $\mathrm{N}-\mathrm{A}$ distances, " $s p^{2}$ " is a hybrid nonbonding DMO centered on the nitrogen atom and situated in the $\mathrm{NH}_{2}$ fragment molecular plane, " $p_{z}$ " is a nonbonding $p$-type orbital centered on the nitrogen atom, and " $h$ " denotes the $1 s$ orbital of the dissociated hydrogen atom.

In Table 1, note the interchange in the role of the first two DMOs between planar and some nonplanar geometries (with $\beta$ less than about $75^{\circ}$ ) for intermediate $\mathrm{N}-\mathrm{A}$ bond lengths (around 1.5-2.0 $\mathrm{\text { }}$ ): for planar geometries, the $\sigma_{\mathrm{N}-\mathrm{A}} \mathrm{DMO}$ is in the plane of the $\mathrm{NH}_{2}$ moiety, whereas the nonbonding $p_{z} \mathrm{DMO}$ is perpendicular to that plane. However, for the above mentioned subset of nonplanar geometries, the $\sigma_{\mathrm{N}-\mathrm{A}} \mathrm{DMO}$ is along the $z$-axis and perpendicular to the NBC plane, with the nonbonding $n$ DMO being now located in the NBC plane. The situation for nonplanar geometries is illustrated in Fig. 1, where the $n$ DMO is taken as the $p_{z}$ orbital for the sake of illustration. Thus, the threefold way along with the overlap criterion for the DMOs at a sequence of geometries along a dissociation path would not provide a consistent list of CSFs for the diabatic prototypes at both planar and nonplanar geometries. In order to define consistent diabatic prototypes, it is necessary to use the more general fourfold way procedure. One reference nonbonding DMO was introduced, whose character transforms continuously between $p_{z}$, being perpendicular to the plane of the NBC moiety for planar geometries, and a nonbonding $n$ orbital perpendicular to the $\mathrm{ABC}$ plane for nonplanar geometries. The new correlation of the DMOs is as shown in Table 2, where it can be seen that now the DMOs keep a uniform character at all geometries.

The need to define a reference orbital for the fourfold way procedure means that one has to choose a standard orientation for the $\mathrm{NH}_{3}$ molecule. In the standard orientation, the nitrogen atom was placed at the origin with one hydrogen atom pointing along the positive $x$-axis; the second hydrogen atom was situated in the $x y$ plane with a positive value of $y$, and with the third hydrogen atom having an arbitrary orientation. A geometry-dependent reference DMO was defined as a DMO centered on the nitrogen atom and having nonbonding character at all molecular configurations. Thus, for separate $\mathrm{NH}_{2}+\mathrm{H}$ fragments, the reference DMO is a $p_{z}$ orbital centered on the nitrogen atom with coefficients computed by the threefold way at the following geometry of the $\mathrm{NH}_{2}$ fragment: $r_{2}=1.5 \AA, r_{3}=1.5 \AA$, $\theta_{1}=120.0^{\circ}$, where $r_{2}$ is the distance from $\mathrm{N}$ to $\mathrm{B}, r_{3}$ is the distance from $\mathrm{N}$ to $\mathrm{C}$, and $\theta_{1}$ is the $\mathrm{BNC}$ bond angle. We label the reference DMO at the dissociation limit as $\chi_{\text {ref }, a}$. When all three $\mathrm{N}-\mathrm{H}$ distances are short, the reference DMO must point in the direction perpendicular to the plane formed by the three hydrogen atoms so as to keep its nonbonding character, even when the molecule does not have a plane of symmetry. In order to generate a reference DMO for an arbitrary geometry, two unit vectors, $\mathbf{v}^{(1)}$ and $\mathbf{v}^{(2)}$, were defined, where $\mathbf{v}^{(1)}$ points along the positive $z$ direction and $\mathbf{v}^{(2)}$ points along the direction normal to the plane of the three hydrogen atoms. The components of these vectors are as follows:

$v_{x}^{(1)}=0, \quad v_{y}^{(1)}=0, \quad v_{z}^{(1)}=1$,

Table 2 Correlation of DMOs between the different $\mathrm{NH}_{3}$ geometries by the fourfold way $(\lambda=1)$

\begin{tabular}{llll}
\hline & Small $\mathrm{N}-\mathrm{A}$ distance $\left(\mathrm{NH}_{3}\right)$ & Intermediate $\mathrm{N}-\mathrm{A}$ distance $\left(\mathrm{NH}_{3}\right)$ & Large $\mathrm{N}-\mathrm{A}$ distance $(\mathrm{NH} 2+\mathrm{H})$ \\
\hline Planar & $\sigma_{\mathrm{N}-\mathrm{A}} p_{\mathrm{z}} R$ & $\sigma_{\mathrm{N}-\mathrm{A}} p_{\mathrm{z}} R$ & $s p^{2} p_{\mathrm{z}} h$ \\
Nonplanar & $\sigma_{\mathrm{N}-\mathrm{A}} n R$ & $\sigma_{\mathrm{N}-\mathrm{A}} n R$ & $s p^{2} p_{\mathrm{z}} h$ \\
\hline
\end{tabular}


$v_{x}^{(2)}=\frac{y_{\mathrm{A}-\mathrm{B}} z_{\mathrm{B}-\mathrm{C}}-z_{\mathrm{A}-\mathrm{B}} y_{\mathrm{B}-\mathrm{C}}}{R_{\mathrm{A}-\mathrm{B}} R_{\mathrm{B}-\mathrm{C}} \sin \theta}$,

$v_{y}^{(2)}=-\frac{x_{\mathrm{A}-\mathrm{B}} z_{\mathrm{B}-\mathrm{C}}-z_{\mathrm{A}-\mathrm{B}} x_{\mathrm{B}-\mathrm{C}}}{R_{\mathrm{A}-\mathrm{B}} R_{\mathrm{B}-\mathrm{C}} \sin \theta}$,

$v_{z}^{(2)}=\frac{x_{\mathrm{A}-\mathrm{B}} y_{\mathrm{B}-\mathrm{C}}-y_{\mathrm{A}-\mathrm{B}} x_{\mathrm{B}-\mathrm{C}}}{R_{\mathrm{A}-\mathrm{B}} R_{\mathrm{B}-\mathrm{C}} \sin \theta}$,

where $\mathbf{R}_{\mathrm{A}-\mathrm{B}}$ and $\mathbf{R}_{\mathrm{B}-\mathrm{C}}$ are bond vectors between atoms $\mathrm{A}$ and $\mathrm{B}$ and atoms $\mathrm{B}$ and $\mathrm{C}$, respectively, and $\theta$ is the angle between these two vectors, $x_{\mathrm{A}-\mathrm{B}}, y_{\mathrm{A}-\mathrm{B}}$, and $z_{\mathrm{A}-\mathrm{B}}$ are components of $\mathbf{R}_{\mathrm{A}-\mathrm{B}}$, and $R_{\mathrm{A}-\mathrm{B}}$ is the magnitude of $\mathbf{R}_{\mathrm{A}-\mathrm{B}}$.

In order to guarantee a smooth, continuous transformation of the reference DMO from the strong-interaction region to separated product fragments, a switching function was defined as

$F=\exp \left(-\left(r_{1}-r_{1}^{0}\right)^{2} / \Delta^{2}\right)$

where $r_{1}$ is the distance from $\mathrm{N}$ to $\mathrm{A}$, and $r_{1}^{0}$ and $\Delta$ are parameters discussed in the next paragraph. This switching function is then used to define a third vector, $\mathbf{v}^{(3)}$, as a linear combination of $\mathbf{v}^{(1)}$ and $\mathbf{v}^{(2)}$ :

$\mathbf{v}^{(3)}=F \mathbf{v}^{(2)}+(1-F) \mathbf{v}^{(1)}$.

In Eq. (3), $r_{1}^{0}$ is a reference $r_{1}$ distance, and $\Delta$ is a parameter controlling the damping of the Gaussian function with distance. After some preliminary test calculations, the values $r_{1}^{0}=1.2 \AA$ and $\Delta=2.0 \AA$ were found to give well-ordered DMOs along paths connecting planar with nonplanar geometries.

The final step is to apply $\mathbf{v}^{(3)}$ to the coefficients of the $\chi_{\text {ref }, a}$ DMO in the contracted Gaussian basis set to obtain the required geometry-dependent reference DMO for the fourfold way. First one can define the triads of numbers abc $=100,010$ and 001. Let $\phi_{\mathrm{abc}}^{\mathrm{CGTO}(1)}, \phi_{\mathrm{abc}}^{\mathrm{CGTO}(2)}$ and $\phi_{\mathrm{abc}}^{\mathrm{CGTO}(3)}$ denote the $p$-type normalized Cartesian contracted Gaussian-type orbitals (CGTOs) centered on the nitrogen atom in the $6-311++\mathrm{G}(3 \mathrm{df}, 3 \mathrm{pd})$ basis set.

$\phi_{\mathrm{abc}}^{\mathrm{CGTO}(1)}=\sum_{i=1}^{3} c_{i} x^{a} y^{b} z^{c} \mathrm{e}^{-\zeta_{i} r^{2}}$,

$\phi_{\mathrm{abc}}^{\mathrm{CGTO}(2)}=x^{a} y^{b} z^{c} \mathrm{e}^{-\zeta 4 r^{2}}$,

$\phi_{\mathrm{abc}}^{\mathrm{CGTO}(3)}=x^{a} y^{b} z^{c} \mathrm{e}^{-\zeta_{5} r^{2}}$.

Likewise, let $\chi_{\text {ref,abc }}^{\mathrm{CGTO}(1)}, \chi_{\text {ref,abc }}^{\mathrm{CGTO}(2)}$ and $\chi_{\text {ref,abc }}^{\mathrm{CGTO}(3)} \mathrm{de}-$ note the coefficients of the reference DMO in the basis of these CGTOs. Finally, $v_{\mathrm{abc}}^{(3)}$ are the components of the $\mathbf{v}^{(3)}$ vector. The equations defining the reference DMO are: $\chi_{\mathrm{ref}, \mathrm{abc}}^{\mathrm{CGTO}(1)}=v_{\mathrm{abc}}^{(3)} \chi_{\mathrm{ref}, a, 001}^{\mathrm{CGTO}(1)}$,
$\chi_{\mathrm{ref}, \mathrm{abc}}^{\mathrm{CGTO}(2)}=v_{\mathrm{abc}}^{(3)} \chi_{\mathrm{ref}, a, 001}^{\mathrm{CGO}(2)}$,
$\chi_{\mathrm{ref}, \mathrm{abc}}^{\mathrm{CGTO}(3)}=v_{\mathrm{abc}}^{(3)} \chi_{\mathrm{ref}, a, 001}^{\mathrm{CGTO}(3)}$.

Recall from the definition of $\chi_{\text {ref }, a}$ that it has nonzero coefficients only for the $p_{z}$-type CGTOs.

The diabatic molecular orbitals (DMOs) obtained by the fourfold way have the following character: $u_{1} \equiv \sigma_{\mathrm{N}-\mathrm{B}}, u_{2} \equiv \sigma_{\mathrm{N}-\mathrm{C}}, u_{3} \equiv n / p_{z}, u_{4} \equiv \sigma_{\mathrm{N}-\mathrm{C}} / s p^{2}, u_{5} \equiv$ $R / h, u_{6} \equiv \sigma_{\mathrm{N}-\mathrm{B}}^{*}, u_{7} \equiv \sigma_{\mathrm{N}-\mathrm{C}}^{*}$. The notation $\mathrm{DMO}_{1} / \mathrm{DMO}_{2}$ refers to the character of that particular DMO at short and long $\mathrm{N}-\mathrm{A}$ bond lengths, respectively. In terms of these DMOs, the dominant CSFs defining each of the three diabatic prototypes, $\chi_{1}, \chi_{2}, \chi_{3}$ for the ground state and $\chi_{4}, \chi_{5}, \chi_{6}$ for the excited state, are:

$\chi_{1}:\left(u_{1}\right)^{2}\left(u_{2}\right)^{2}\left(u_{3}\right)^{2}\left(u_{4}\right)^{2}\left(u_{5}\right)^{0}\left(u_{6}\right)^{0}\left(u_{7}\right)^{0}$,

$\chi_{2}:\left(u_{1}\right)^{2}\left(u_{2}\right)^{2}\left(u_{3}\right)^{2}\left(u_{4}\right)^{1}\left(u_{5}\right)^{1}\left(u_{6}\right)^{0}\left(u_{7}\right)^{0}$,

$\chi_{3}:\left(u_{1}\right)^{2}\left(u_{2}\right)^{2}\left(u_{3}\right)^{2}\left(u_{4}\right)^{0}\left(u_{5}\right)^{2}\left(u_{6}\right)^{0}\left(u_{7}\right)^{0}$,

$\chi_{4}:\left(u_{1}\right)^{2}\left(u_{2}\right)^{2}\left(u_{3}\right)^{1}\left(u_{4}\right)^{2}\left(u_{5}\right)^{1}\left(u_{6}\right)^{0}\left(u_{7}\right)^{0}$,

$\chi_{5}:\left(u_{1}\right)^{2}\left(u_{2}\right)^{2}\left(u_{3}\right)^{1}\left(u_{4}\right)^{1}\left(u_{5}\right)^{2}\left(u_{6}\right)^{0}\left(u_{7}\right)^{0}$,

$\chi_{6}:\left(u_{1}\right)^{2}\left(u_{2}\right)^{1}\left(u_{3}\right)^{2}\left(u_{4}\right)^{2}\left(u_{5}\right)^{1}\left(u_{6}\right)^{0}\left(u_{7}\right)^{0}$.

The fourfold way procedure provides a smooth diabatic matrix in most of the dynamically relevant configuration space. The exceptions are some geometries where at least two of the $\mathrm{N}-\mathrm{H}$ distances are relatively long (equal to or longer than $1.5 \AA$ ), when the trisector angle $\beta$ is smaller than about $60^{\circ}$ and for certain values of the HNH angles. Those points were removed from the global fit.

The coordinates used for the grids and the fitting are defined in Fig. 2. Note that in addition to the bond angles $\theta_{1}, \theta_{2}$, and $\theta_{3}$, Fig. 2 shows the projected bond angles $\theta_{1}^{\prime}, \theta_{2}^{\prime}$ and $\theta_{3}^{\prime}$ that were originally introduced by Léonard et al. [19]. In addition we use the trisector angle $\beta$ also introduced by Léonard et al. [19]. Most of the points for the fitting were contained in a regular grid constructed in coordinates $\left(r_{1}, r_{2}, r_{3}, \theta_{1}^{\prime}, \theta_{2}^{\prime}, \theta_{3}^{\prime}, \beta\right)$ defined in Fig. 2 as follows: $r_{1}$ was varied between 0.8 and $5.0 \AA$, and $r_{2}$ and $r_{3}$ were varied between 0.8 and $1.5 \AA$ for a total of 44 different $\left(r_{1}, r_{2}, r_{3}\right)$ values, which were combined with 182 sets of the four angles $\left(\theta_{1}^{\prime}, \theta_{2}^{\prime}, \theta_{3}^{\prime}, \beta\right)$. These sets of four angles were obtained by combining 14 sets of projected bond angles $\left(\theta_{1}^{\prime}, \theta_{2}^{\prime}, \theta_{3}^{\prime}\right)$ with 13 values of the trisector angle $\beta$, which is varied between $30^{\circ}$ and $90^{\circ}$ inclusive with a 5-degree regular increment. The groups of $\left(\theta_{1}^{\prime}, \theta_{2}^{\prime}, \theta_{3}^{\prime}\right)$ angles are the following: $(120,120$, 120); $(120,150,90)$; $(180,120,60) ;(120,90,150)$; $(90$, 


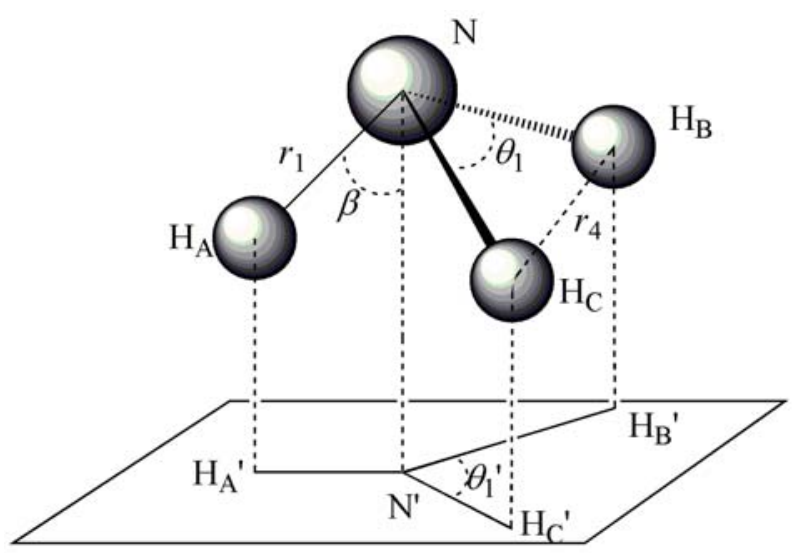

Fig. 2 Internal coordinates used for fitting the diabatic surfaces and their couplings. $r_{1}, r_{2}$ and $r_{3}$ are the $\mathrm{N}-\mathrm{A}, \mathrm{N}-\mathrm{B}$ and $\mathrm{N}-\mathrm{C}$ bond distances, respectively. $r_{4}, r_{5}$ and $r_{6}$ are the $\mathrm{H}_{\mathrm{B}}-\mathrm{H}_{\mathrm{C}}, \mathrm{H}_{\mathrm{A}}-\mathrm{H}_{\mathrm{C}}$ and $\mathrm{H}_{\mathrm{A}}-\mathrm{H}_{\mathrm{B}}$ bond distances, respectively. $\theta_{1}$ is the bond angle $\mathrm{H}_{\mathrm{B}} \mathrm{NH}_{\mathrm{C}}, \theta_{2}$ is the bond angle $\mathrm{H}_{\mathrm{A}} \mathrm{NH}_{\mathrm{C}}, \theta_{3}$ is the bond angle $\mathrm{H}_{\mathrm{A}} \mathrm{NH}_{\mathrm{B}}$, and $\beta$ is the trisector angle. The prime denotes the projection of the atoms on a plane perpendicular to the $\mathrm{NN}^{\prime}$ direction

150, 120); (180, 90, 90); (150, 90, 60); $(90,120,150)$; $(180,60,120) ;(150,60,90) ;(120,60,60) ;(150,60,150)$; $(150,90,120)$; and $(150,120,90)$. Thus, the grid contains a total of 8,008 points. The ranges of the coordinates and diabatic energies are shown in Table 3. The diabatic potential energies and couplings were plotted versus the trisector angle $\beta$ and those points showing nonsmooth behavior were removed from the fit. All of the removed points had $\beta$ angles less than $60^{\circ}$, as explained above. Some duplicated points, that is, points with different values of the coordinates defined above but with the same set of internuclear distances were also removed from the fit. After these operations, the remaining 5,624 points were included in the fit.

The diabatic potential energy matrix was computed at additional sets of points to improve the fitting in par- ticular regions of configuration space. A total of 2,812 additional points with the coordinates and diabatic energies presented in rows $2-14$ of Table 3 were computed, from which 2,603 were included in the final fitting. The following numbers of points refer to those originally computed. Thus, 800 points were generated close to the ground-state $\mathrm{NH}_{3}$ minimum (GS min in Table 3), with relatively small displacements from the equilibrium geometry, and 1,200 additional points were chosen to map the region around the transition state for $\mathrm{N}-\mathrm{A}$ dissociation on the $V_{2}$ PES (ES N-A saddle point in Table 3). In the labels, GS and ES denote ground state and excited state, respectively. To aid in the refinement of the frequencies of the $\mathrm{NH}_{3}$ minimum on the $V_{2} \mathrm{PES}$, a normal mode analysis was carried out at the statespecific CASSCF(8,7)/6-311++G(3df, 3pd) level, and an additional 47 points were chosen along the six Cartesian normal mode vectors (ES min I and II in Table 3). Likewise, to assist in obtaining accurate stationary-point geometries and frequencies for the $\mathrm{NH}_{2}$ fragments, 73 points suitable for the ground state and 48 points suitable for the excited state were added $\left(\mathrm{NH}_{2}\left(\tilde{X}^{2} B_{1}\right)+\mathrm{H}\right.$ and $\mathrm{NH}_{2}\left(\tilde{A}^{2} A_{1}\right)+\mathrm{H}$ in Table 3$)$.

Additional points were also chosen in repulsive regions of the PESs (Repulsive I-V in Table 3) to guide the fitting of the repulsive interactions [see Eq. (16) below]. The sets of points I and II (about 200 points in total) were generated randomly in regions where preliminary fits generated spurious negative energies. The set of points III contains 20 points along the $\mathrm{N}-\mathrm{A}$ stretch curve with $r_{1}$ in the range $0.2-5.0 \AA$, and set IV contains 18 points with fixed $\mathrm{N}-\mathrm{H}$ distances with $\theta_{3}^{\prime}$ varying in such a way that one of the $\mathrm{H}-\mathrm{H}$ distances decreases from $1.55 \AA$ to about $0.25 \AA$. Finally, set V contains 100 points with very high energies $(>300 \mathrm{eV})$. An additional 312 points were computed to refine the long-distance tail of the PESs.

Table 3 Coordinate and diabatic energy ranges for all the computed points

\begin{tabular}{lccccccccc}
\hline & $r_{2}(\AA)$ & $r_{3}(\AA)$ & $r_{1}(\AA)$ & $\theta_{1}^{\prime}(\mathrm{deg})$ & $\theta_{2}^{\prime}(\mathrm{deg})$ & $\theta_{3}^{\prime}(\mathrm{deg})$ & $\beta(\mathrm{deg})$ & $U_{11}(\mathrm{eV})$ & $U_{22}(\mathrm{eV})$ \\
\hline Regular grid & $0.8-1.5$ & $0.8-1.5$ & $0.8-5.0$ & $90-150$ & $60-150$ & $60-150$ & $30-90$ & $0.1-30.4$ & $4.7-37.3$ \\
GS min & $1.0-1.1$ & $1.0-1.1$ & $1.0-1.1$ & $87-153$ & $87-153$ & $87-153$ & $60-90$ & $0.1-2.3$ & $5.9-8.2$ \\
ES N-A saddle point & $0.99-1.05$ & $0.99-1.05$ & $1.05-1.95$ & $102-153$ & $105-130$ & $75-155$ & $75-90$ & $0.4-5.6$ & $5.4-8.9$ \\
ES min I & $0.9-1.3$ & $0.9-1.5$ & $0.9-1.5$ & $105-145$ & $60-170$ & $60-170$ & $55-90$ & $0.4-7.3$ & $5.9-13.7$ \\
ES min II & $1.03-1.07$ & $1.00-1.07$ & $1.0-1.07$ & $117-123$ & $116-123$ & $116-123$ & $86-92$ & $0.3-0.6$ & $5.8-6.0$ \\
$\mathrm{NH}_{2}\left(\tilde{X}^{2} B_{1}\right)+\mathrm{H}$ & $0.95-2.80$ & $0.95-5.00$ & 10.0 & 90 & $130-170$ & $100-180$ & 90 & $6.3-14.7$ & $4.8-14.7$ \\
$\mathrm{NH}_{2}\left(\tilde{A}^{2} A_{1}\right)+\mathrm{H}$ & $0.95-2.80$ & $0.95-5.00$ & 10.0 & 90 & $90-130$ & $100-180$ & 90 & $6.1-14.7$ & $5.4-14.7$ \\
Repulsive I & $0.8-1.5$ & $1.02-1.5$ & $1.02-1.5$ & $10-180$ & $10-180$ & $10-180$ & $40-90$ & $14-103$ & $15-106$ \\
Repulsive II & $0.5-0.6$ & $0.5-0.7$ & $0.6-1.5$ & $10-150$ & $30-180$ & $40-150$ & $10-90$ & $26-134$ & $32-138$ \\
Repulsive III & 1.02 & 1.02 & $0.2-5.0$ & 120 & 120 & 120 & 65 & $0-217$ \\
Repulsive IV & 1.02 & 1.02 & 1.02 & $124-179$ & $122-152$ & $115-17$ & $54-64$ & $0.2-29.3$ & $6.8-34.8$ \\
Repulsive V & $0.2-0.8$ & $0.4-0.8$ & $0.2-0.4$ & $10-40$ & $10-40$ & $10-40$ & $10-20$ & $302-305$ & $309-312$ \\
Long N-A distance & 1.04 & 1.04 & $3.3-4.1$ & $60-180$ & $60-150$ & $60-150$ & $30-90$ & $6.2-9.2$ & $4.9-6.4$ \\
\hline
\end{tabular}


A total of 8,227 points were included in the fitting.

Since the two diabatic surfaces cross at certain geometries, we will name the ground adiabatic potential energy surface as $V_{1}$, the first singlet-excited adiabatic potential surface as $V_{2}$, the diabatic potential energy surface with lower energy around the ground-state equilibrium geometry of $\mathrm{NH}_{3}$ as $U_{11}$, and the higher-energy one as the $U_{22}$ surface. Throughout the entire article, the zero of energy is at the equilibrium geometry of the ground adiabatic state of $\mathrm{NH}_{3}$. Thus all values of the adiabatic surfaces $V_{1}$ and $V_{2}$ and the diabatic $U_{11}$ and $U_{22}$ are positive except $V_{1}=0$ at the lowest energy geometry.

\section{Stationary-point data}

Theoretical state-specific CASSCF as well as experimental (or best-estimate theoretical) data [20-31] are presented in Tables 4 and 5. The data in the tables serve two purposes, namely (1) they are used to constrain the fitted PESs to reproduce the experimental
$\mathrm{NH}_{3}\left(\tilde{X}^{1} A_{1}\right) \rightarrow \mathrm{NH}_{2}\left(\tilde{X}^{2} B_{1}\right)+\mathrm{H}$ and $\mathrm{NH}_{3}\left(\tilde{X}^{1} A_{1}\right) \rightarrow$ $\mathrm{NH}_{2}\left(\tilde{A}^{2} A_{1}\right)+\mathrm{H}$ dissociation energies and the $\mathrm{NH}_{3}$ $\left(\tilde{X}^{1} A_{1}\right) \rightarrow \mathrm{NH}_{3}\left(\tilde{A}^{1} A^{\prime \prime}{ }_{2}\right)$ and $\mathrm{NH}_{2}\left(\tilde{X}^{2} B_{1}\right) \rightarrow \mathrm{NH}_{2}\left(\tilde{A}^{2}\right.$ $A_{1}$ ) excitation energies (see below), and (2) they are used to provide a comparison of the ab initio and fitted geometry and frequencies of the $\mathrm{NH}_{3}$ minima and of the $\mathrm{NH}_{2}$ fragment in their electronic ground and first excited states.

The dissociation energies $\left(D_{0}\right)$ and the excitation energies $\left(T_{0}\right)$ at $0 \mathrm{~K}$ have been directly measured with good accuracy. To obtain the equilibrium dissociation energies $D_{e}$ and the equilibrium excitation energies $T_{e}$ [i.e., the energy differences on the PESs excluding the zero-point vibrational energies (ZPEs)], one needs to estimate anharmonic ZPEs.

The $D_{0}$ of the reaction $\mathrm{NH}_{3}\left(\tilde{X}^{1} A_{1}\right) \rightarrow \mathrm{NH}_{2}\left(\tilde{X}^{2} B_{1}\right)+$ $\mathrm{H}$ has been extensively studied [32]. Here we adopt the lower experimental photodissociation value of 4.602 $\pm 0.002 \mathrm{eV}$ determined by Mordaunt et al. [24], which claims the highest accuracy and agrees very well with the latest compilation of Ruscic et al. [32]. Mordaunt

Table 4 State-specific CASSCF(8,7)/6-311++G(3df, 3pd) geometries ( $\AA$ and degree) and vibrational frequencies $\left(\mathrm{cm}^{-1}\right)$, state-averaged MC-QDPT energies (eV), experimental data, and analytical function results for $\mathrm{NH}_{3}$

\begin{tabular}{|c|c|c|c|}
\hline Quantity & Present fit & Theoretical & Best estimate $^{a}$ \\
\hline \multicolumn{4}{|l|}{$\mathbf{V}_{1}$} \\
\hline $\begin{array}{l}\text { Equilibrium geometry }\left(C_{3 \mathrm{v}}\right) \\
r_{1} \\
\theta_{1}\end{array}$ & $\begin{array}{l}1.016 \\
106.1\end{array}$ & $\begin{array}{l}1.023 \\
105.0\end{array}$ & $\begin{array}{l}1.012[20] \\
106.7[20]\end{array}$ \\
\hline $\begin{array}{l}\text { Vibrational frequencies } \\
\omega_{1}\left(a_{1}\right) \omega_{2}\left(a_{1}\right) \\
\omega_{3}(e) \omega_{4}(e)\end{array}$ & $\begin{array}{cc}3397.4 & 1235.2 \\
3628.0 & 1750.2\end{array}$ & $\begin{array}{cc}3358.7 & 1144.4 \\
3473.8 & 1700.2\end{array}$ & $\begin{array}{l}3484.6[21] 1084.1^{b},[22 \\
3623.7[21] 1677.8[21]\end{array}$ \\
\hline $\begin{array}{l}\mathrm{ZPE} \\
D_{e} \text { for } \mathrm{NH}_{3}\left(\tilde{X}^{1} A_{1}\right) \rightarrow \mathrm{NH}_{2}\left(\tilde{X}^{2} B_{1}\right)+\mathrm{H} \\
\mathbf{V}_{2}\end{array}$ & $\begin{array}{l}0.954 \\
5.016\end{array}$ & $\begin{array}{l}0.921 \\
4.790\end{array}$ & $\begin{array}{l}0.941(0.925[23]) \\
5.016\left[4.602^{b},[24]\right]\end{array}$ \\
\hline $\begin{array}{l}\text { Equilibrium geometry }\left(D_{3 \mathrm{~h}}\right) \\
r_{1}\end{array}$ & 1.039 & 1.036 & $1.055(8)[25]$ \\
\hline $\begin{array}{l}\text { Vibrational frequencies } \\
\omega_{1}\left(a_{1}^{\prime}\right) \omega_{2}\left(a_{2}^{\prime \prime}\right) \\
\omega_{3}\left(e^{\prime}\right) \omega_{4}\left(e^{\prime}\right) \\
\mathrm{ZPE} \\
T_{e} \text { for } \mathrm{NH}_{3}\left(\tilde{X}^{1} A_{1}\right) \rightarrow \mathrm{NH}_{3}\left(\tilde{A}^{1} A_{2}^{\prime \prime}\right)\end{array}$ & $\begin{array}{ll}2776.9 & 891.2 \\
3041.2 & 1329.9 \\
0.769 & \\
5.923 & \end{array}$ & $\begin{array}{ll}2959.3 & 314.6 \\
3213.6 & 1437.1 \\
0.780 & \\
5.870 & \end{array}$ & $\begin{array}{l}2,870892 \\
3,0201,110[25] \\
0.745[25](0.724[25]) \\
5.923[5.722[25]]\end{array}$ \\
\hline $\begin{array}{l}\text { Saddle point geometry }\left(C_{2 v}\right) \\
r_{1} r_{2} r_{3} \\
\theta_{1} \theta_{2} \theta_{3}\end{array}$ & $\begin{array}{ccc}1.289 & 1.040 & 1.040 \\
112.1 & 123.9 & 123.9\end{array}$ & $\begin{array}{ccc}1.274 & 1.038 & 1.038 \\
113.4 & 123.3 & 123.3\end{array}$ & $\begin{array}{lll}1.298 & 1.040 & 1.040 \\
112.4 & 123.8 & 123.8^{b},[26]\end{array}$ \\
\hline $\begin{array}{l}\text { Vibrational frequencies } \\
\omega_{1}\left(a_{1}\right) \omega_{2}\left(a_{1}\right) \omega_{6}\left(a_{1}\right) \\
\omega_{3}\left(b_{1}\right) \omega_{4}\left(b_{2}\right) \omega_{5}\left(b_{2}\right) \\
\text { Saddle point energy without ZPE } \\
\text { Classical barrier height }\end{array}$ & $\begin{array}{lll}3056.9 & 1417.6 & 1866.7 \mathrm{i} \\
941.1 & 3078.2 & 569.9 \\
6.14 & & \\
0.22 & & \end{array}$ & $\begin{array}{lll}3115.4 & 1503.5 & 2608.8 \mathrm{i} \\
916.6 & 3333.4 & 664.8 \\
6.11 & & \\
0.24 & & \end{array}$ & $\begin{array}{l}6.19^{\mathrm{b}},[26] \\
0.29^{\mathrm{b}},[26]\end{array}$ \\
\hline
\end{tabular}

Zero-point energies corrected for anharmonicity are given in parentheses, following harmonic values. $D_{0}$ and $T_{0}$ are given in brackets

${ }^{a}$ From experiments except where indicated otherwise

$\mathrm{b}$ Theoretical value 
Table 5 State-specific CASSCF(8,7)/6-311++G(3df, 3pd) geometries ( $\AA$ and degree) and frequencies $\left(\mathrm{cm}^{-1}\right)$, state-averaged MC-QDPT energies $(\mathrm{eV})$, experimental data, and analytical function results for $\mathrm{NH}_{2}$

\begin{tabular}{|c|c|c|c|}
\hline Quantity & Present fit & Theoretical & Best estimate \\
\hline \multicolumn{4}{|l|}{$\mathbf{V}_{1}$} \\
\hline $\begin{array}{l}\mathrm{NH}_{2}\left(\tilde{X}^{2} B_{1}\right) \text { equilibrium } \\
R_{1} \\
\theta_{1}\end{array}$ & $\begin{array}{l}\text { ry } \\
1.034 \\
103.1\end{array}$ & $\begin{array}{l}1.037 \\
101.8\end{array}$ & $\begin{array}{l}1.024[27] \\
103.4[27]\end{array}$ \\
\hline $\begin{array}{l}\text { Vibrational frequencies } \\
\omega_{1}\left(a_{1}\right) \omega_{2}\left(a_{1}\right) \omega_{3}\left(b_{2}\right) \\
v_{1}\left(a_{1}\right) v_{2}\left(a_{1}\right) v_{3}\left(b_{2}\right)\end{array}$ & $\begin{array}{lll}3212.0 & 1600.7 & 3553.1 \\
- & & \end{array}$ & $\begin{array}{lll}3244.5 & 1556.3 & 3340.5 \\
- & & \end{array}$ & 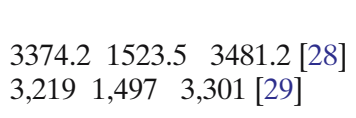 \\
\hline $\begin{array}{l}\mathrm{ZPE} \\
\mathbf{V}_{2}\end{array}$ & 0.519 & 0.505 & $0.519[28](0.511[28])$ \\
\hline $\begin{array}{l}\mathrm{NH}_{2}\left(\tilde{A}^{2} A_{1}\right) \text { equilibrium } \\
r_{1} \\
\theta_{1}\end{array}$ & $\begin{array}{l}\text { ry } \\
0.992 \\
143.4\end{array}$ & $\begin{array}{l}1.000 \\
142.8\end{array}$ & $\begin{array}{l}1.004[30] \\
144[30]\end{array}$ \\
\hline $\begin{array}{l}\text { Vibrational frequencies } \\
\omega_{1}\left(a_{1}\right) \omega_{2}\left(a_{1}\right) \omega_{3}\left(b_{2}\right) \\
v_{1}\left(a_{1}\right) v_{2}\left(a_{1}\right) v_{3}\left(b_{2}\right) \\
\mathrm{ZPE}\end{array}$ & $\begin{array}{lll}3629.1 & 1008.4 & 3889.1 \\
- & & \\
0.529 & & \end{array}$ & $\begin{array}{lll}3592.8 & 1054.1 & 3897.0 \\
- & & \\
0.530 & & \end{array}$ & 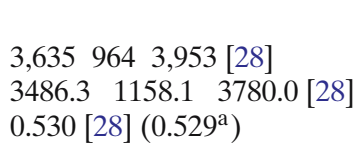 \\
\hline $\begin{array}{l}\mathrm{NH}_{2}\left(\tilde{X}^{2} B_{1}\right) \rightarrow \mathrm{NH}_{2}\left(\tilde{A}^{2}\right. \\
T_{0} \\
T_{\mathrm{e}}\end{array}$ & $\begin{array}{l}\text { itation energy } \\
- \\
1.361\end{array}$ & - & $\begin{array}{l}1.379[31] \\
1.361\end{array}$ \\
\hline
\end{tabular}

Zero-point energies corrected for anharmonicity are given in parentheses, following harmonic values

${ }^{a}$ Estimated using Eq. (8)

et al. also calculated the $D_{e}$ of this reaction (5.023 \pm $0.003 \mathrm{eV}$ ). Due to the lack of experimental harmonic vibrational frequencies and their anharmonic couplings for the $\mathrm{NH}_{2}\left(\tilde{X}^{2} B_{1}\right)$ radical, they used the following equation to obtain the $\mathrm{ZPE}$ of the $\mathrm{NH}_{2}\left(\tilde{X}^{2} B_{1}\right)$ radical:

$\mathrm{ZPE}\left(\mathrm{NH}_{2}\right)=\mathrm{ZPE}\left(\mathrm{NH}_{2}\right)^{\text {Theor }} \frac{\mathrm{ZPE}\left(\mathrm{NH}_{3}\right)^{\mathrm{Exp}}}{\mathrm{ZPE}\left(\mathrm{NH}_{3}\right)^{\text {Theor }}}$,

where the theoretical ZPEs are calculated with purely theoretical anharmonic parameters. However, the theoretical parameters were calculated at different levels of theory; in particular MP4/6-31G(d,p) was used for ammonia [33] while multireference configuration-interaction was used for the $\mathrm{NH}_{2}\left(\tilde{X}^{2} B_{1}\right)$ radical. Here we adopt the value of Handy et al. [23], $0.925 \mathrm{eV}$ (7461.53 $\left.\mathrm{cm}^{-1}\right)$ for the $\mathrm{ZPE}$ of $\mathrm{NH}_{3}\left(\tilde{X}^{1} A_{1}\right)$; this agrees very well with the value, $0.925 \mathrm{eV}\left(7460.93 \mathrm{~cm}^{-1}\right)$ of Gatti et al. [34]. For the $\mathrm{ZPE}$ of $\mathrm{NH}_{2}\left(\tilde{X}^{2} B_{1}\right)$, we adopt the high level theoretical value of $0.511 \mathrm{eV}$ of Gabriel et al. [28], which agrees very well with other high-level theoretical results, in particular, $0.512 \mathrm{eV}$ of Martin et al. [22] and $0.512 \mathrm{eV}$ of Demaison et al. [35]. With these new choices of data, the $D_{e}$ of the reaction $\mathrm{NH}_{3}\left(\tilde{X}^{1} A_{1}\right) \rightarrow$ $\mathrm{NH}_{2}\left(\tilde{X}^{2} B_{1}\right)+\mathrm{H}$ is then calculated to be $5.016 \mathrm{eV}$, which is very close to the $5.023 \mathrm{eV}$ given by Mordaunt et al. [24]. We will use the value $5.016 \mathrm{eV}$.
To calculate $D_{e}$ of the reaction $\mathrm{NH}_{3}\left(\tilde{X}^{1} A_{1}\right) \rightarrow \mathrm{NH}_{2}$ $\left(\tilde{A}^{2} A_{1}\right)+\mathrm{H}$, one needs to obtain the $T_{e}$ excitation energy for $\mathrm{NH}_{2}\left(\tilde{X}^{2} B_{1}\right) \rightarrow \mathrm{NH}_{2}\left(\tilde{A}^{2} A_{1}\right)$. The $T_{0}$ excitation energy has been accurately determined as $1.379 \mathrm{eV}$ $\left(11122.23 \pm 0.05 \mathrm{~cm}^{-1}\right)$ [31]. Since the $\mathrm{ZPE}$ of $\mathrm{NH}_{2}\left(\tilde{A}^{2}\right.$ $A_{1}$ ) corrected for anharmonicity is not directly available from the literature due to the lack of harmonic force constants and their anharmonic couplings, we used a similar strategy as Mordaunt et al. to estimate it:

$$
\begin{aligned}
& \mathrm{ZPE}\left(\mathrm{NH}_{2}, \tilde{A}^{2} A_{1}\right) \\
& =\mathrm{ZPE}\left(\mathrm{NH}_{2}, \tilde{X}^{2} B_{1}\right) \frac{\left(\mathrm{ZPE}^{\mathrm{F}}+\mathrm{ZPE}^{\mathrm{H}}\right)_{\mathrm{NH}_{2}, \tilde{A}^{2} A_{1}}}{\left(\mathrm{ZPE}^{\mathrm{F}}+\mathrm{ZPE}^{\mathrm{H}}\right)_{\mathrm{NH}_{2}, \tilde{X}^{2} B_{1}}}
\end{aligned}
$$

where

$$
\begin{aligned}
\mathrm{ZPE}^{\mathrm{F}} & =\frac{1}{2} \sum_{i} v_{i}, \\
\mathrm{ZPE} & =\frac{1}{2} \sum_{i} \omega_{i},
\end{aligned}
$$

where $v_{i}$ is a fundamental frequency, and $\omega_{i}$ is a harmonic frequency. The use of Eq. (8) is based on the fact that $\frac{1}{2}\left(\mathrm{ZPE}^{\mathrm{F}}+\mathrm{ZPE}{ }^{\mathrm{H}}\right)$ is a good approximation to the 
accurate $\mathrm{ZPE}$ [36]. The $\mathrm{ZPE}$ of $\mathrm{NH}_{2}\left(\tilde{A}^{2} A_{1}\right)$ is calculated to be $0.529 \mathrm{eV}$ by this procedure. With this value, the $\mathrm{NH}_{2}\left(\tilde{X}^{2} B_{1}\right) \rightarrow \mathrm{NH}_{2}\left(\tilde{A}^{2} A_{1}\right) T_{e}$ excitation energy is calculated to be $1.361 \mathrm{eV}$, and a $D_{e}$ of $6.377 \mathrm{eV}$ for the $\mathrm{NH}_{3}\left(\tilde{X}^{1} A_{1}\right) \rightarrow \mathrm{NH}_{2}\left(\tilde{A}^{2} A_{1}\right)+\mathrm{H}$ reaction is obtained.

The fourth important energy difference that we try to reproduce with the analytical function is the $\mathrm{NH}_{3}\left(\tilde{X}^{1} A_{1}\right)$ $\rightarrow \mathrm{NH}_{3}\left(\tilde{A}^{1} A_{2}^{\prime \prime}\right) T_{\mathrm{e}}$ excitation energy. The $T_{0}$ of this excitation has been determined as $5.722 \mathrm{eV}\left(46,150 \mathrm{~cm}^{-1}\right)$ by Henck et al. [25] and $5.719 \mathrm{eV}\left(46,130 \mathrm{~cm}^{-1}\right)$ by Douglas [37]. Henck et al. also estimated $T_{e}$ using the ab initio ZPE of $\mathrm{NH}_{3}\left(\tilde{X}^{1} A_{1}\right)$ calculated by Hargiss and Ermler [33] and the experimental ZPE of $\mathrm{NH}_{3}\left(\tilde{A}^{1} A_{2}^{\prime \prime}\right)$ that they determined $\left(0.724 \mathrm{eV}, 5,840 \mathrm{~cm}^{-1}\right)$, which gives a value of $5.960 \mathrm{eV}\left(48,070 \pm 200 \mathrm{~cm}^{-1}\right)$. Using the best available $\mathrm{ZPE}$ for $\mathrm{NH}_{3}\left(\tilde{X}^{1} A_{1}\right)$, which is $0.925 \mathrm{eV}$ $\left(7461.53 \mathrm{~cm}^{-1}\right)$ [23] as determined by Handy et al., $T_{e}$ is calculated to be $5.923 \mathrm{eV}$, slightly lower than the value given by Henck et al. [25], but closer to the best available theoretical value of $5.902 \mathrm{eV}$ calculated by Bach et al. [26]. We will use the value of $5.923 \mathrm{eV}$.

\section{Functional forms and fitting procedures}

\subsection{Coordinate system used}

Ten internal coordinates are used to fit the two potential energy surfaces and their coupling. In particular we used three $\mathrm{N}-\mathrm{H}$ bond distances $\left(r_{1}, r_{2}, r_{3}\right)$, three $\mathrm{HNH}$ bond angles $\left(\theta_{1}, \theta_{2}, \theta_{3}\right)$, three $\mathrm{H}-\mathrm{H}$ bond distances $\left(r_{4}, r_{5}, r_{6}\right)$, and a trisector angle $\beta$ (Fig. 2). The trisector angle was originally introduced in earlier studies in order to better describe the inversion potential in the ground electronic state $[19,23]$. The three $\mathrm{H}-\mathrm{H}$ bond distances are used to add a repulsive interaction (see Sect. 4.2) at very small $\mathrm{H}-\mathrm{N}-\mathrm{H}$ bond angles to correct spurious nonphysical energies of the previous fitting functions. Notice that we used $\left(r_{1}, r_{2}, r_{3}, \theta_{1}^{\prime}, \theta_{2}^{\prime}, \theta_{3}^{\prime}, \beta\right)$ for the regular grids, but we used $\left(r_{1}, r_{2}, r_{3}, r_{4}, r_{5}, r_{6}, \theta_{1}, \theta_{2}, \theta_{3}, \beta\right)$ for fitting.

\subsection{Functional forms}

The $U_{11}$ surface was fitted to the following functional form:

$$
\begin{aligned}
E(\mathbf{Q})= & \sum_{\substack{i \leq j \leq k \\
l \leq m \leq n \\
p}} C_{i j k l m n p}^{(1)} \sum_{\alpha} A_{i j k l m n p}^{(1)}\left(\mathbf{P}_{\alpha} \mathbf{Q}\right) \\
& +F\left(r_{1}, r_{2}, r_{3}, r_{4}, r_{5}, r_{6}\right)+E_{\mathrm{D}}\left(r_{1}, r_{2}, r_{3}, r_{4}, r_{5}, r_{6}\right),
\end{aligned}
$$

where $\mathbf{P}_{\alpha}$ is the permutation operator used in the previous study [1], $\alpha$ (which equals $1,2, \ldots, 6$ ) labels the permutations of hydrogen atoms $\mathrm{A}, \mathrm{B}$, and $\mathrm{C}$, and

$$
\begin{aligned}
& A_{i j k l m n p}^{(1)}(\mathbf{Q})= B_{i}\left(r_{1}\right) B_{j}\left(r_{2}\right) B_{k}\left(r_{3}\right) \\
& \times g\left(l, \theta_{1}, r_{2}, r_{3}\right) g\left(m, \theta_{2}, r_{1}, r_{3}\right), \\
& \times g\left(n, \theta_{3}, r_{1}, r_{2}\right) h\left(p, \beta, r_{1}, r_{2}, r_{3}\right), \\
& B_{i}(r)=\left[1-\mathrm{e}^{\left.-\gamma^{(1)}\left(r-r_{0}^{(1)}\right)\right]^{i},}\right.\left\{\left[\cos \left(\theta_{0}\right)-\cos \left(\theta_{1}\right)\right] \mathrm{e}^{-\delta^{(1)}\left(r_{2}^{2}+r_{3}^{2}\right)}\right\}, \\
& g\left(l, \theta_{1}, r_{2}, r_{3}\right)=\left\{\left[\cos \left(\theta_{0}\right)-\cos \left(\theta_{2}\right)\right] \mathrm{e}^{-\delta^{(1)}\left(r_{1}^{2}+r_{3}^{2}\right)}\right\}^{m}, \\
& g\left(m, \theta_{2}, r_{1}, r_{3}\right)=\left\{\left[\cos \left(\theta_{0}\right)-\cos \left(\theta_{3}\right)\right] \mathrm{e}^{-\delta^{(1)}\left(r_{1}^{2}+r_{2}^{2}\right)}\right\}, \\
& g\left(n, \theta_{3}, r_{1}, r_{2}\right)= \\
& h\left(p, \beta, r_{1}, r_{2}, r_{3}\right)=1+\left\{1-\cos \left[p\left(\beta-\frac{\pi}{2}\right)\right]\right\} \\
& \times \mathrm{e}^{-\delta^{(1)}\left(r_{1}^{2}+r_{2}^{2}+r_{3}^{2}\right)}, \\
& F\left(r_{1}, r_{2}, r_{3}, r_{4}, r_{5}, r_{6}\right)=B_{\mathrm{NH}}^{(1)} \sum_{i=1}^{3} \frac{\mathrm{e}^{-\beta_{\mathrm{NH}}^{(1)}\left(r_{i}-r_{01}^{(1)}\right)^{2}}}{r_{i}} \\
&+B_{\mathrm{HH}}^{(1)} \sum_{i=4}^{6} \frac{\mathrm{e}^{-\beta_{\mathrm{HH}}^{(1)}\left(r_{i}-r_{01}^{(1)}\right)^{2}}}{r_{i}},
\end{aligned}
$$

with $0 \leq i, j, k \leq 2, i+j+k \leq 4, l+m+n \leq 2, i+j+$ $k+l+m+n \geq 1$, and $1 \leq p \leq 2$. In Eq. (14), $\theta_{0}$ is the ground-sate equilibrium $\mathrm{HNH}$ bond angle which is fixed to the experimental value [20] of $106.68^{\circ}$; and $r_{01}^{(1)}$ is fixed to $-0.2 \AA$. There are a total of 64 linear coefficients, which include $62 C_{i j k l m n p}^{(1)}$ plus $B_{\mathrm{NH}_{1}}^{(1)}$ and $B_{\mathrm{HH}}^{(1)}$, and five additional nonlinear parameters, $\gamma(1), r_{0}^{(1)}, \delta(1), \beta_{\mathrm{NH}_{1}}^{(1)}$, and $\beta_{\mathrm{HH}}^{(1)}$, determined by fitting to the MC-QDPT energies.

First the values of the 69 fitting parameters specified above were obtained by fitting (discussed in Sect. 4.3) to the data sets described in Sect. 2 with $E_{\mathrm{D}}=0$. Then $E_{\mathrm{D}}$ was included in Eq. (11) to constrain the analytical function to give the experimental dissociation limit and excitation energies and to eliminate unphysical values at very short $\mathrm{N}-\mathrm{H}$ bond distances. The correction function used is:

$$
\begin{aligned}
E_{\mathrm{D}}\left(r_{1}, r_{2}, r_{3}, r_{4}, r_{5}, r_{6}\right)= & \Delta E_{1}^{(1)}+E_{\mathrm{R}}\left(r_{1}, r_{2}, r_{3}\right) \\
& +\Delta E_{2}^{(1)} S_{c}\left(r_{1}, r_{2}, r_{3}\right),
\end{aligned}
$$

where

$$
\begin{aligned}
& E_{\mathrm{R}}\left(r_{1}, r_{2}, r_{3}\right)=B_{\mathrm{NH}_{2}}^{(1)} \sum_{i=1}^{3} \frac{\mathrm{e}^{-\beta_{\mathrm{NH}_{2}}^{(1)}\left(r_{i}-r_{01}^{(1)}\right)^{2}}}{r_{i}} . \\
& S_{c}\left(r_{1}, r_{2}, r_{3}\right)=\sum_{i=1}^{3} \frac{1+\tanh \left\lfloor\eta_{1}^{(1)}\left(r_{i}-2 r_{e}^{(1)}\right)\right\rfloor}{2} .
\end{aligned}
$$


$E_{\mathrm{R}}$ is a function that adds a steep repulsive wall at very short $\mathrm{N}-\mathrm{H}$ bond distances. The parameters $B_{\mathrm{NH}_{2}}^{(1)}$ and $\beta_{\mathrm{NH}_{2}}^{(1)}$ in the function $E_{\mathrm{R}}$ are manually adjusted so that there are no unphysical regions (with negative energies) at very short $\mathrm{N}-\mathrm{H}$ bond distances. The parameter $r_{e}^{(1)}$ in the function $S_{\mathrm{c}}$ is fixed to the experimental $\mathrm{N}-\mathrm{H}$ bond distance of $1.024 \AA$ of $\mathrm{NH}_{2}\left(\tilde{X}^{2} B_{1}\right)$ [23], while $\eta_{1}^{(1)}$ is manually adjusted so that the correction is largest when one $\mathrm{N}-\mathrm{H}$ bond is broken but is negligible when the $\mathrm{NH}_{3}$ geometry is close to the minimum equilibrium geometry. $\Delta E_{1}^{(1)}$ and $\Delta E_{2}^{(1)}$ are manually adjusted to reproduce the $D_{e}$ of the $\mathrm{NH}_{3}\left(\tilde{X}^{1} A_{1}\right) \rightarrow \mathrm{NH}_{2}\left(\tilde{A}{ }^{2} A_{1}\right)+\mathrm{H}$ reaction and to force the adiabatic $V_{1}$ energy of the minimum equilibrium geometry of $\mathrm{NH}_{3}$ on the $V_{1}$ potential energy surface to be as close to zero as possible.

In the previous work, the $U_{22}$ surface was fitted using a multiconfigurational representation involving two surfaces $W_{11}$ and $W_{22}$ [1]. In the present work, it is represented with just one configuration. The function form used is similar to that of $U_{11}$. However, to fit the excitedstate minimum and the saddle point for the $\mathrm{N}-\mathrm{H}$ bond dissociation on the $U_{22}$ surface simultaneously, $i, j$ and $k$ are allowed to be equal to 3 , but when they are equal to 3 , function $B_{i}(r)$ is changed to

$B_{i}\left(r_{1}, r_{2}, r_{3}\right)=\mathrm{e}^{-\alpha^{(2)}\left(r_{1}-r_{02}^{(2)}\right)^{2}} \mathrm{e}^{-\delta^{(2)}\left(r_{2}^{2}+r_{3}^{2}\right)}, \quad i=3$.

When $i, j$, and $k$ are less than or equal to 2, Eq. (13) is still used. Function $g\left(l, \theta_{1}, r_{2}, r_{3}\right)$ is changed to

$g\left(l, \theta_{1}, r_{2}, r_{3}\right)=1+\left[\cos \left(\theta_{0}\right)-\cos \left(\theta_{1}\right)\right]^{l} \mathrm{e}^{-\delta^{(2)}\left(r_{2}^{2}+r_{3}^{2}\right)}$.

The third difference between the functions used for $U_{11}$ and $U_{22}$ is that $h\left(p, \beta, r_{1}, r_{2}, r_{3}\right)$ is changed to

$$
\begin{aligned}
h\left(p, \beta, r_{1}, r_{2}, r_{3}\right) \\
=1+\left\{1-\cos \left[p\left(\beta-\frac{\pi}{2}\right)\right]+\frac{1}{2} \frac{k^{(2)}\left(\beta-\frac{\pi}{2}\right)^{2}}{C^{(2)}+\left(\beta-\frac{\pi}{2}\right)^{2}}\right\} \\
\quad \times \mathrm{e}^{-\delta^{(2)}\left(r_{1}^{2}+r_{2}^{2}+r_{3}^{2}\right)} .
\end{aligned}
$$

The reason for using Eq. (22) instead of Eq. (15) for $U_{22}$ is that the harmonic vibrational frequency of the umbrella vibration motion for the excited-state minimum is too low at the level of theory used to prepare the data sets (see Table 4). This additional term effectively makes the surface steeper when the $\beta$ angle deviates from the equilibrium value $(\pi / 2)$. The ranges of the $i, j, k, l, m, n$, and $p$ values are slightly different from those used for $U_{11}$. The ranges for $U_{22}$ are $0 \leq i, j$, $k \leq 3,0 \leq l, m, n \leq 2$, and $0 \leq p \leq 2$ with additional constraints that $i=j=k=l=m=n=0$ when $p=0 ; 0 \leq l+m+n \leq 2, i+j+k+l+m+n \geq 1$, when $1 \leq p \leq 2$ and $0 \leq i+j+k \leq 3 ; i$, $j$, and $k \neq 2,0 \leq l+m+n \leq 2, i+j+k+l+m+n \geq 1$, when $1 \leq p \leq 2$ and $4 \leq i+j+k \leq 5$. For the $U_{22}$ surface, $\theta_{0}$ is fixed to the equilibrium value of $120^{\circ}$, and $r_{01}^{(2)}$ is fixed to $-0.2 \AA$. $B_{\mathrm{NH}_{1}}^{(2)}, \beta_{\mathrm{NH}_{1}}^{(2)}, B_{\mathrm{HH}}^{(2)}$ and $\beta_{\mathrm{HH}}^{(2)}$ are the same as those used for $U_{11}$, and $C^{(2)}$ is fixed to a small value of $0.05 \mathrm{rad}^{2}$. A total of 71 linear $C_{i j k l m n p}^{(2)}$ coefficients and

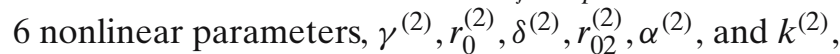
are determined by fitting to the MC-QDPT energies $\left(k^{(2)}\right.$ is a linear coefficient, but is treated as a nonlinear parameter in the fitting).

For the functions [Eqs. (17)-(19)] used to correct to the experimental dissociation limits after fitting to the MC-QDPT energies, the parameters $B_{\mathrm{NH}_{2}}^{(2)}$ and $\beta_{\mathrm{NH}_{2}}^{(2)}$ are manually adjusted. The parameters used in the function $S_{\mathrm{c}}$ are the same as those used for $U_{11}$, i.e., $\eta_{1}^{(2)}=\eta_{1}^{(1)}$ and $r_{e}^{(2)}=r_{e}^{(1)} . \Delta E_{1}^{(2)}$ and $\Delta E_{2}^{(2)}$ are manually adjusted to reproduce three experimental energy differences: (1) $D_{\mathrm{e}}$ for the $\mathrm{NH}_{3}\left(\tilde{X}^{1} A_{1}\right) \rightarrow \mathrm{NH}_{2}\left(\tilde{X}^{2} B_{1}\right)+\mathrm{H}$ reaction; (2) $T_{e}$ for the $\mathrm{NH}_{3}\left(\tilde{X}^{1} A_{1}\right) \rightarrow \mathrm{NH}_{3}\left(\tilde{A}^{1} A_{2}^{\prime \prime}\right)$ excitation; and (3) $T_{e}$ for the $\mathrm{NH}_{2}\left(\tilde{X}^{2} B_{1}\right) \rightarrow \mathrm{NH}_{2}\left(\tilde{A}^{2} A_{1}\right)$ excitation.

For fitting the diabatic coupling surface $U_{12}$, the previous functional form [1] is used:

$$
U_{12}(\mathbf{Q})=\sum_{\substack{i \leq j \leq k \\ l \leq m \leq n \\ p}} C_{i j k l m n p}^{(3)} \sum_{\alpha} B_{i j k l m n p}^{(3)}\left(\mathbf{P}_{\alpha} \mathbf{Q}\right),
$$

where

$B_{i j k l m n p}^{(3)}(\mathbf{Q})=r_{1}^{i} r_{2}^{j} r_{3}^{k} F\left(r_{1}\right) F\left(r_{2}\right) F\left(r_{3}\right) \theta_{1}^{l} \theta_{2}^{m} \theta_{3}^{n} G(p, \beta)$,

with

$F(r)=1-\tanh \left(r-r_{0}^{(3)}\right)$,
$G(p, \beta)=\sin \left[p\left(\beta-\frac{\pi}{2}\right)\right]$,

where $0 \leq i, j, k \leq 2,0 \leq l, m, n \leq 2$, and $3 \leq p \leq 5$ with additional constraints $i+j+k \leq 2, l+m+n \leq 2$, and $i+j+k+l+m+n \geq 1$. There are a total of 45 linear $C_{i j k l m n p}^{(3)}$ coefficients and only one nonlinear parameter, $r_{0}^{(3)}$, to be determined.

\subsection{Fitting procedure}

The linear coefficients were obtained by a linear least squares fitting routine for given nonlinear parameters. The nonlinear parameters are fitted using a simplex algorithm. To find the best parameters, random initial guesses were used, and the fitting procedure was 
repeated until the error could not be lowered. The error minimized in the nonlinear fitting procedure is calculated by:

$$
\begin{aligned}
E r r & =\frac{\sum_{i=1}^{8227} w_{i}\left|E_{i}^{\mathrm{F}}-E_{i}^{\mathrm{MC}}\right|}{\sum_{i=1}^{8227} w_{i}} \\
& +\frac{\sum_{j=1}^{8227} \sum_{i=1}^{8227} w_{i} w_{j}\left|\left(E_{i}^{\mathrm{F}}-E_{j}^{\mathrm{F}}\right)-\left(E_{i}^{\mathrm{MC}}-E_{j}^{\mathrm{MC}}\right)\right|}{\sum_{j=1}^{8227} \sum_{i=1}^{8227} w_{i} w_{j}}
\end{aligned}
$$

where $w_{i}$ is the weight for the given energy, $E_{i}^{\mathrm{F}}$ is the energy given by the fitting function with the linear coefficients determined in the linear squares fitting with the same set of weights for the given nonlinear parameters, and $E_{i}^{\mathrm{MC}}$ is the energy to be fitted. For the fitting of the $U_{11}$ surface, the weights are calculated by state on the $U_{22}$ surface:

$\chi_{i}=10 \mathrm{e}^{-50 \min \left[\left(r_{i}-r_{t}\right), i=1,3\right]}$,

$\lambda_{i}=25 \mathrm{e}^{-50\left(\frac{r_{1}+r_{2}+r_{3}}{3}-r_{0}\right)^{2}}$,

where $r_{t}=1.30 \AA$ is the dissociating $\mathrm{N}-\mathrm{H}$ distance in the transition state, and $r_{0}=1.05 \AA$ is the equilibrium $\mathrm{N}-\mathrm{H}$ distance of the planar $D_{3 \mathrm{~h}}$ minimum optimized by Dixon [38].

To fit the $U_{12}$ surface, a uniform weighting scheme was used. It should be noted that since the functional form used for the $U_{12}$ surface is an odd function of $(\beta-\pi / 2)$, only those geometries with $\beta<\pi / 2(7,036$ out of 8,227$)$ in the whole dataset were used to fit the $U_{12}$ surface.

All the values for the linear coefficients and fitted nonlinear parameters are provided in the supporting information. ${ }^{1}$

$$
w_{i}=\left\{\begin{array}{l}
\left(\frac{3.1}{U_{11}(i)+0.1}\right)^{1.3}, \quad \text { when } \frac{3.1}{U_{11}(i)+0.1}<1 \quad \text { and } \quad r_{1}<2.0 \AA \\
\left(\frac{3.1}{U_{11}(i)+0.1}\right)^{1.2}, \quad \text { when } \frac{3.1}{U_{11}(i)+0.1} \geq 1 \quad \text { and } \quad r_{1}<2.0 \AA \\
3\left(\frac{3.1}{U_{11}(i)+0.1}\right)^{1.2}, \quad \text { when } U_{11}(i) \leq 7.0 \mathrm{eV}, \quad \text { and } \quad 2.0 \leq r_{1} \leq 5.0 \AA \\
35\left(\frac{3.1}{U_{11}(i)+0.1}\right)^{1.2}, \quad \text { when } U_{11}(i) \leq 7.0 \mathrm{eV}, \quad \text { and } \quad r_{1}>5.0 \AA \\
\left(\frac{3.1}{U_{11}(i)+0.1}\right)^{1.3}, \quad \text { when } U_{11}(i)>7.0 \mathrm{eV}, \quad \text { and } \quad r_{1} \geq 2.0 \AA
\end{array}\right.
$$

where $U_{11}$ is the MC-QDPT value in $\mathrm{eV}$. Notice that extra weight was given to the dissociated points (that is, those with one $\mathrm{N}-\mathrm{H}$ distance greater than $5.0 \AA$ ); this was done to force the function to have the right dissociation limit.

For the $U_{22}$ surface, the weights used are

\subsection{Availability}

The fitted surfaces and coupling, including analytic gradients in Cartesian coordinates, have been deposited in the POTLIB $[39,40]$ potential-energy surface library, which is freely available online [41].

$w_{i}=\left\{\begin{array}{l}\left(\frac{7.0}{U_{22}(i)}\right)^{2}+\chi_{i}+\lambda_{i}, \quad \text { when } \frac{7.0}{U_{22}(i)} \geq 1 \quad \text { and } \quad r_{1}<1.9 \AA \\ 7\left(\frac{7.0}{U_{22}(i)}\right)^{2}, \quad \text { when } \frac{7.0}{U_{22}(i)} \geq 1.1 \text { and } \quad 1.9 \leq r_{1}<3.0 \AA \\ 7.5\left(\frac{7.0}{U_{22}(i)}\right)^{2}, \quad \text { when } \frac{7.0}{U_{22}(i)} \geq 1.1 \quad \text { and } \quad 3 \leq r_{1} \leq 5.0 \AA \\ 5\left(\frac{7.0}{U_{22}(i)}\right)^{2}, \quad \text { when } \frac{7.0}{U_{22}(i)} \geq 1 \quad \text { and } \quad r_{1}>5.0 \AA\end{array}\right.$,

otherwise

$w_{i}=\left\{\begin{array}{l}\left(\frac{7.0}{U_{22}(i)}\right)^{1.6}, \quad \text { when } \frac{7.0}{U_{22}(i)}<0.5 \\ \left(\frac{7.0}{U_{22}(i)}\right)^{1.3}, \quad \text { when } 0.5 \leq \frac{7.0}{U_{22}(i)}<1, \\ \left(\frac{7.0}{U_{22}(i)}\right)^{2}, \quad \text { when } \frac{7.0}{U_{22}(i)} \geq 1\end{array}\right.$,

where the energies are in $\mathrm{eV}$ and $\chi_{i}$ and $\lambda_{i}$ are functions of the three $\mathrm{N}-\mathrm{H}$ distances chosen to add extra weight to the data points around the planar $D_{3 \mathrm{~h}}$ minimum and to the data points around the $\mathrm{N}-\mathrm{H}$ dissociation transition

\section{Discussion}

The discussion is organized as follows: in the next two paragraphs we discuss the accuracy of the preliminary fits before correcting the four critical energy differences (i.e., the mean unsigned errors for the fits with $\left.E_{\mathrm{D}}=0\right)$. Then, we compare the properties of some

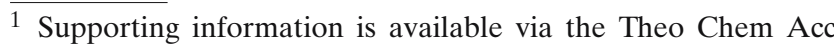
journal homepage.
} 
Table 6 Mean unsigned error of the fitted $U_{11}$ and $U_{22}$ energies with respect to the state-averaged MC-QDPT energies for several energy ranges (all energies in $\mathrm{eV}$ )

\begin{tabular}{lrlllll}
\hline$U_{11}$ & & & & \multicolumn{2}{l}{$U_{22}$} \\
\cline { 1 - 3 }$\Delta E$ & $N^{\mathrm{a}}$ & MUE & & $\Delta E$ & $N^{\mathrm{a}}$ & MUE \\
\hline $0-1$ & 806 & 0.01 & & $0-5$ & 198 & 0.03 \\
$0-2$ & 1,628 & 0.02 & & $0-6$ & 1,088 & 0.04 \\
$0-3$ & 1,906 & 0.03 & & $0-7$ & 3,771 & 0.06 \\
$0-4$ & 2,147 & 0.04 & & $0-8$ & 4,930 & 0.11 \\
$0-5$ & 2,627 & 0.06 & & $0-9$ & 6,202 & 0.17 \\
$0-6$ & 3,198 & 0.09 & & $0-10$ & 6,914 & 0.21 \\
$0-7$ & 4,022 & 0.11 & & $0-11$ & 7,304 & 0.23 \\
$0-8$ & 4,896 & 0.13 & & $0-12$ & 7,551 & 0.24 \\
$0-9$ & 5,721 & 0.16 & & $0-13$ & 7,708 & 0.25 \\
$0-10$ & 6,712 & 0.20 & & $0-14$ & 7,806 & 0.26 \\
\hline
\end{tabular}

${ }^{a}$ Number of data points in the corresponding energy range, $\Delta E$

Table 7 Mean unsigned error of the fitted $U_{12}$ energies to the state-averaged MC-QDPT energies for several energy ranges (all energies in $\mathrm{eV}$ )

${ }^{a}$ Number of data points in the corresponding energy range, $\Delta E$

\begin{tabular}{lll}
\hline$\Delta E$ & $N^{\mathrm{a}}$ & MUE \\
\hline $0-0.2$ & 1,992 & 0.08 \\
$0-0.4$ & 3,136 & 0.09 \\
$0-0.6$ & 4,034 & 0.09 \\
$0-0.8$ & 4,802 & 0.09 \\
$0-1.0$ & 5,518 & 0.10 \\
$0-1.2$ & 5,983 & 0.10 \\
$0-1.4$ & 6,334 & 0.11 \\
$0-1.6$ & 6,616 & 0.12 \\
$0-1.8$ & 6,802 & 0.12 \\
$0-2.0$ & 6,914 & 0.12 \\
\hline
\end{tabular}

stationary points obtained with the full functional forms (with $E_{\mathrm{D}} \neq 0$ ) to the best available results, and finally we present mappings of the conical intersection seams.

The mean unsigned errors for preliminary fits are listed in Tables 6 and 7. Experimentally, the dissociated $\mathrm{NH}_{2}\left(\tilde{A}^{2} A_{1}\right)+\mathrm{H}$ is at least $6.902 \mathrm{eV}$ above the bottom of the potential energy well of the $\mathrm{NH}_{3}$ minimum on the adiabatic $V_{1}$ surface (the zero of energy for the current fitting). For fitting $U_{11}$, the MUE for energies between 0 and $7 \mathrm{eV}$ is $0.11 \mathrm{eV}$, which we consider satisfactory. For fitting $U_{22}$, since we add extra weight to the points around the $D_{3 \mathrm{~h}}$ minimum and the dissociation transition state, the MUE of the fitted $U_{22}$ energies between 5.7 and $6.7 \mathrm{eV}$ is $0.05 \mathrm{eV}$. For all the energies below $7 \mathrm{eV}$, the MUE of the fitted $U_{22}$ energies is $0.06 \mathrm{eV}$, which can also be considered satisfactory. For the fitting of the $U_{12}$ surface, the MUE of the fitted $U_{12}$ energies below $2 \mathrm{eV}$ is $0.12 \mathrm{eV}$. The error is slightly larger than those of the $U_{11}$ and $U_{22}$ surfaces.

Having obtained the diabatic potential-energy surfaces and their coupling, the adiabatic surfaces $V_{1}$ and $V_{2}$ can be obtained by [1]
Table 8 Mean unsigned error (eV) of the fitted $V_{1}$ and $V_{2}$ energies to the state-averaged MC-QDPT energies for several energy ranges (all energies in $\mathrm{eV}$ )

\begin{tabular}{lrlllll}
\hline$V_{1}$ & & & & \multicolumn{2}{l}{$V_{2}$} \\
\cline { 7 - 8 }$\Delta E$ & $N^{\mathrm{a}}$ & MUE & & $\Delta E$ & $N^{\mathrm{a}}$ & MUE \\
\hline $0-1$ & 829 & 0.01 & & $0-5$ & 0 & - \\
$0-2$ & 1,634 & 0.02 & & $0-6$ & 281 & 0.04 \\
$0-3$ & 1,948 & 0.03 & & $0-7$ & 2,560 & 0.05 \\
$0-4$ & 2,258 & 0.05 & & $0-8$ & 3,246 & 0.08 \\
$0-5$ & 3,170 & 0.07 & & $0-9$ & 4,362 & 0.14 \\
$0-6$ & 4,127 & 0.09 & & $0-10$ & 5,690 & 0.23 \\
$0-7$ & 5,503 & 0.10 & & $0-11$ & 6,669 & 0.28 \\
$0-8$ & 6,367 & 0.12 & & $0-12$ & 7,244 & 0.31 \\
$0-9$ & 7,338 & 0.14 & & $0-13$ & 7,599 & 0.32 \\
$0-10$ & 7,680 & 0.15 & & $0-14$ & 7,730 & 0.33 \\
\hline
\end{tabular}

a Number of data points in the corresponding energy range, $\Delta E$

$$
\begin{aligned}
V_{1(2)}= & \frac{1}{2}\left\{U_{11}(\mathbf{Q})+U_{22}(\mathbf{Q})\right. \\
& \left.\mp \sqrt{\left[U_{11}(\mathbf{Q})-U_{22}(\mathbf{Q})\right]^{2}+4 U_{12}(\mathbf{Q})^{2}}\right\} .
\end{aligned}
$$

Although our fit does not use $V_{1}$ and $V_{2}$ energies at all, the MUE errors of the fitted $V_{1}$ and $V_{2}$ energies are reasonably good (Table 8): The MUE of the fitted $V_{1}$ energies below $7 \mathrm{eV}$ is $0.10 \mathrm{eV}$, and that of the fitted $V_{2}$ energies below $7 \mathrm{eV}$ is just $0.05 \mathrm{eV}$.

To characterize the quality of the fitted potential energy surfaces, we have compared the geometries and vibrational frequencies of some important stationary points to the best previous results. The results are presented in Tables 4 and 5. The $\mathrm{N}-\mathrm{H}$ bond distance of $\mathrm{NH}_{3}$ minimum on the adiabatic ground state is $1.016 \AA$, very close to the experimental value of $1.012 \AA$ [20]. The HNH bond angle is just half degree smaller than the experimental value. Although we did not explicitly fit to the experimental harmonic vibrational frequencies of the ground state $\mathrm{NH}_{3}$ minimum, the fitted frequencies agree reasonably well with experiment. Table 8 indicates that the fitting around the ground-state minimum is very accurate, with an MUE of just $0.01 \mathrm{eV}$ for the energy range $0-1 \mathrm{eV}$. Therefore, the discrepancy between the vibrational frequencies given by the fitted function and those experimental values must be due mainly to the inaccuracy of the MC-QDPT method. The $\mathrm{N}-\mathrm{H}$ bond distance of the $\mathrm{NH}_{3}$ minimum on the adiabatic excited state $\tilde{A}^{1} A_{2}^{\prime \prime}$ is $1.039 \AA$, in good agreement with the experimental value of $1.055 \AA$ [25]. The harmonic vibrational frequencies are also in fairly good agreement with experimental values.

We optimized the transition state for $\mathrm{N}-\mathrm{H}$ dissociation on the diabatic $U_{22}$ surface using the optimizer in the Gaussian 03 program [18] with its "external" 


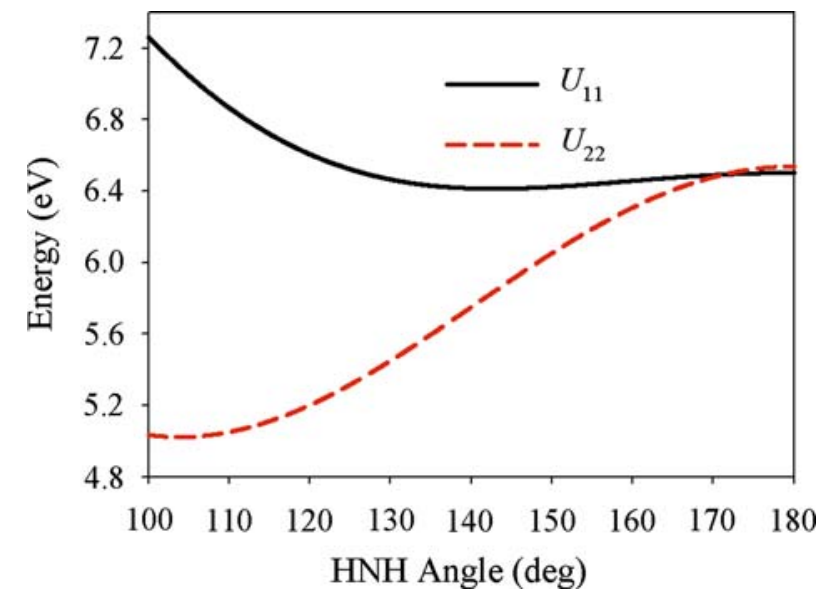

Fig. 3 One-dimensional potential-energy profiles of $\mathrm{NH}_{2}$ with the two $\mathrm{N}-\mathrm{H}$ bond distances fixed at $1.02 \AA$. The solid line is $U_{11}$, and the dashed line is $U_{22}$

functionality. The dissociating $\mathrm{N}-\mathrm{H}$ bond distance at the optimized saddle point with the current analytical function is slightly shorter than the best available value of $1.298 \AA$ [26] by $0.009 \AA$, while the other two N-H bond distances are very close to the literature values [26]. For the dynamics simulation of the photodissociation of ammonia, a property that is probably more important is the barrier height. The classical barrier height relative to energy of the planar $\mathrm{NH}_{3}\left(\tilde{A}^{1} A_{2}^{\prime \prime}\right)$ minimum given by the analytical function is 0.22 , and $0.07 \mathrm{eV}$ lower than the best literature value of $0.29 \mathrm{eV}$ [26].

For the minima of the ground-state and the first doublet excited-state $\mathrm{NH}_{2}$, the agreement between the current fitting and experiments is very good. The agreement between the fitted vibrational frequencies and the best available values is also fairly good. It should be noted that since we manually adjust the function to give the four experimental energy differences, they are exactly the same as the experimental values. The $U_{11}\left(V_{2}\right)$ and $U_{22}\left(V_{1}\right)$ energies of $\mathrm{NH}_{2}$ are degenerate at linear geometries. Since the $U_{11}$ and $U_{22}$ potential surfaces were fitted with different functional forms, it is hard for the analytical function to produce identical $U_{11}$ and $U_{22}$ energies for the linear geometries. In Fig. 3 the $U_{11}$ and $U_{22}$ energies of $\mathrm{NH}_{2}$ were plotted respect to the $\mathrm{HNH}$ angle. The current analytical functions give almost the same $U_{11}$ and $U_{22}$ energies when $\mathrm{NH}_{2}$ is linear.

As pointed out in the previous paper on the $\mathrm{NH}_{3}$ PESs, [1] the conical intersection is at most four dimensional, since when $V_{1}$ equals to $V_{2}, U_{22}$ must equal to $U_{11}$, and $U_{12}$ must vanish according to Eq. (32). Apparently, $U_{12}$ vanishes only for planar structures. In Fig. 4, we present one-dimensional plots of $U_{11}$ and $U_{22}$ as functions of one $\mathrm{N}-\mathrm{H}$ distance $\left(r_{1}\right)$ for the planar
Table 9 Geometries ( $\AA$ and degrees) and energies (eV) of the conical intersections in Fig. 4, and the lowest-energy conical intersections given by the current analytical functions and the literature

\begin{tabular}{lllllllll}
\hline & $r_{1}$ & $r_{2}$ & $r_{3}$ & $\theta_{1}$ & $\theta_{2}$ & $\theta_{3}$ & $V_{1}$ & $V_{2}$ \\
\hline Fig. 4a & 1.628 & 1.628 & 1.628 & 120.0 & 120.0 & 120.0 & 8.74 & 8.74 \\
Fig. 4b & 1.952 & 1.028 & 1.028 & 104.0 & 128.0 & 128.0 & 5.17 & 5.17 \\
Fig. 4c & 1.832 & 1.002 & 1.050 & 102.2 & 164.0 & 93.8 & 5.27 & 5.27 \\
$C_{2 \mathrm{v}}{ }^{\mathrm{a}}$ & 1.990 & 1.023 & 1.023 & 107.9 & 126.0 & 126.0 & 5.16 & 5.16 \\
$C_{2 \mathrm{v}}$ & 1.955 & 1.021 & 1.021 & 110 & 125 & 125 & 5.11 & 5.11 \\
\hline
\end{tabular}

a The lowest-energy conical intersection geometry given by the current analytical functions

b From [42]

structures with the constraint of $D_{3 \mathrm{~h}}$ (Fig. 4a), $C_{2 \mathrm{v}}$ (Fig. 4b), and $C_{\mathrm{s}}$ (Fig. 4c) symmetry. The geometrical parameters other than $r_{1}$ are optimized to minimize $U_{22}$ subject to the specific symmetry. The geometries and energies of the three conical intersection points in Fig. 4 are listed in Table 9. The plot in Fig. 4a shows two conical intersection points. The one with higher energy corresponds to the dissociated $\mathrm{N}+3 \mathrm{H}$, which is qualitatively correct. The geometry of the one presented in Table 9 is the one with lower energy. One can see that the conical intersection with $D_{3 \mathrm{~h}}$ symmetry has the shortest $\mathrm{N}-\mathrm{H}$ bond distance, while that with $C_{2 \mathrm{v}}$ symmetry has the longest $\mathrm{N}-\mathrm{H}$ bond distance. These scans, though, do not locate the lowest-energy conical intersections for these symmetries. To find the lowest-energy conical intersection we minimize the function

$F(\mathbf{Q})=\frac{1}{2}\left[U_{11}(\mathbf{Q})+U_{22}(\mathbf{Q})\right]+\mu\left[U_{11}(\mathbf{Q})-U_{22}(\mathbf{Q})\right]^{2}$,

where $\mu$ is an adjustable parameter. As $\mu$ is increased, the geometry that minimizes this function (for planar geometries) is the lowest-energy conical intersection. We varied $\mu$ from $1,000 E_{\mathrm{h}}^{-1}$ to $50,000 E_{\mathrm{h}}^{-1}$ until the final geometry converges. The final resulting geometry is given in Table 9.

Yarkony found several conical intersection geometries with both $C_{2 \mathrm{v}}$ and $C_{\mathrm{s}}$ symmetries [42]. The lowestenergy conical intersection has $C_{2 \mathrm{v}}$ symmetry. The one we obtained is higher in energy by $0.05 \mathrm{eV}$. This is because the present fitting exactly reproduces the dissociation energies and the $\mathrm{NH}_{3}\left(\tilde{X}^{1} A_{1}\right) \rightarrow \mathrm{NH}_{3}\left(\tilde{A}^{1} A_{2}^{\prime \prime}\right)$ equilibrium excitation energy $\left(T_{e}\right)$, which are all higher than the corresponding theoretical values [42]. Therefore, the whole $U_{22}$ surface, and the $U_{11}$ surface with large $\mathrm{N}-\mathrm{H}$ bond distance, are all shifted upwards, and the energies of the conical intersections are shifted upwards accordingly.

In Fig. 5 we plot the three-dimensional diabatic and adiabatic surfaces varying one $\mathrm{N}-\mathrm{H}$ distance $\left(r_{1}\right)$ and 

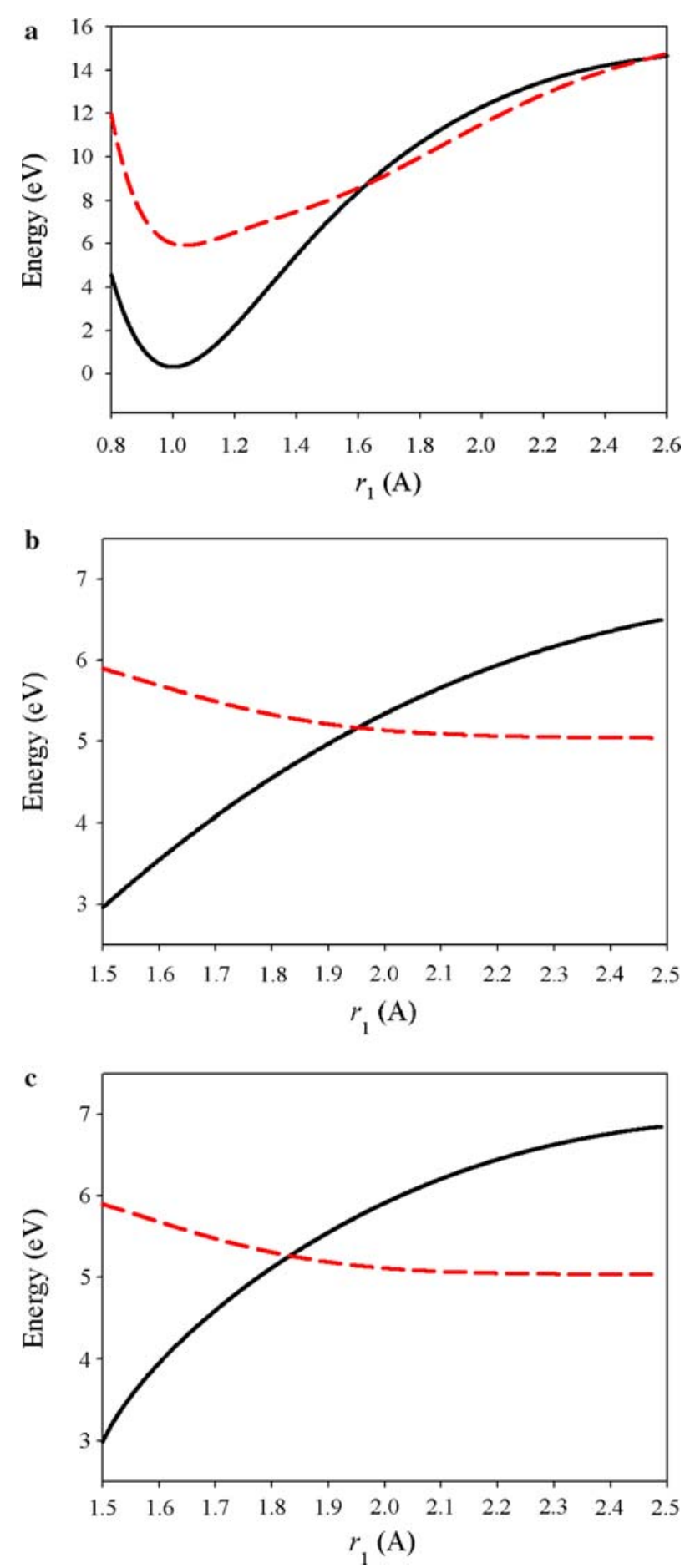

Fig. 4 One-dimensional potential-energy profiles of the relaxed scans on the diabatic $U_{22}$ PES of the planar $\mathrm{NH}_{3}$ with the constraint of: a $D_{3 \mathrm{~h}}$ symmetry; b $C_{2 \mathrm{v}}$ symmetry; c $C_{\mathrm{s}}$ symmetry. The solid line is $U_{11}$, and the dashed line is $U_{22}$

the trisector angle $\beta$ while keeping the two other $\mathrm{N}-\mathrm{H}$ bond distances fixed at the planar equilibrium geometry $(1.039 \AA)$ on the $U_{22}$ surface and the three projected angles $\left(\theta_{1}^{\prime}, \theta_{2}^{\prime}, \theta_{3}^{\prime}\right)$ on the plane fixed at $120^{\circ}$. Figure $5 \mathrm{a}$
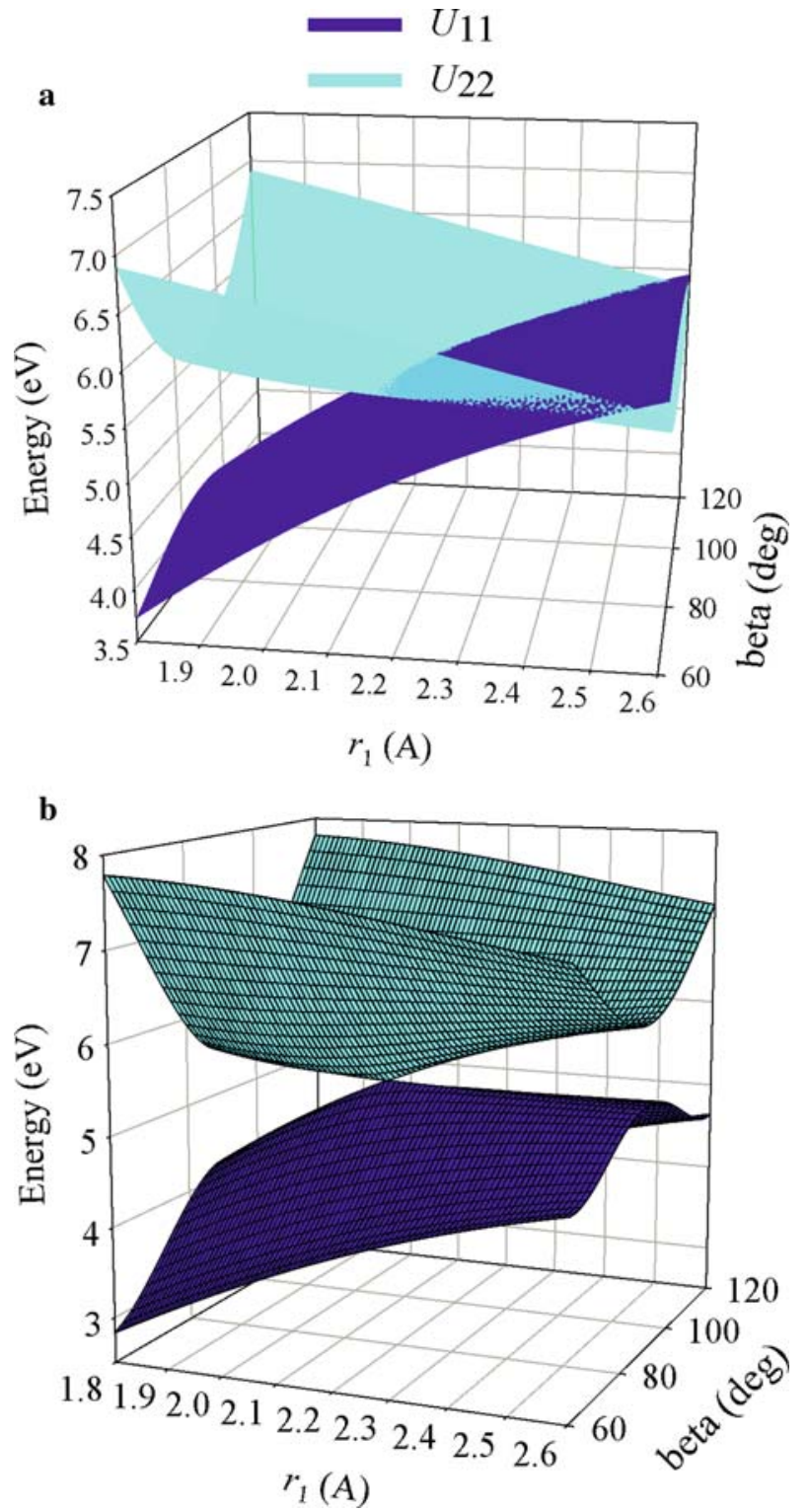

Fig. 5 Three-dimensional plots of a the $U_{11}$ and $U_{22}$ diabatic PESs showing the diabatic crossing of the two surfaces and $\mathbf{b}$ the $V_{1}$ and $V_{2}$ adiabatic potential-energy surfaces of ammonia showing the conical intersection along the N-A stretch $\left(r_{1}\right)$ and the inversion angle $\beta$. The other two $\mathrm{N}-\mathrm{H}$ bond distances are fixed at $1.039 \AA$, and the three projected bond angles $\left(\theta_{1}^{\prime}, \theta_{2}^{\prime}, \theta_{3}^{\prime}\right)$ are fixed at $120^{\circ}$

shows the crossing between the $U_{11}$ and $U_{22}$ surfaces. Although $U_{11}$ crosses $U_{22}$ for both planar and nonplanar geometries, only the former crossings are conical intersections since $U_{12}$ is not zero for nonplanar structures.

In Fig. 6 we present three-dimensional (Fig. 6a) and contour (Fig. 6b) plots of the conical intersection seam with the constraint of $C_{2 \mathrm{v}}$ symmetry. The scan is carried out with the external function of the Gaussian 03 program with other geometrical parameters optimized 

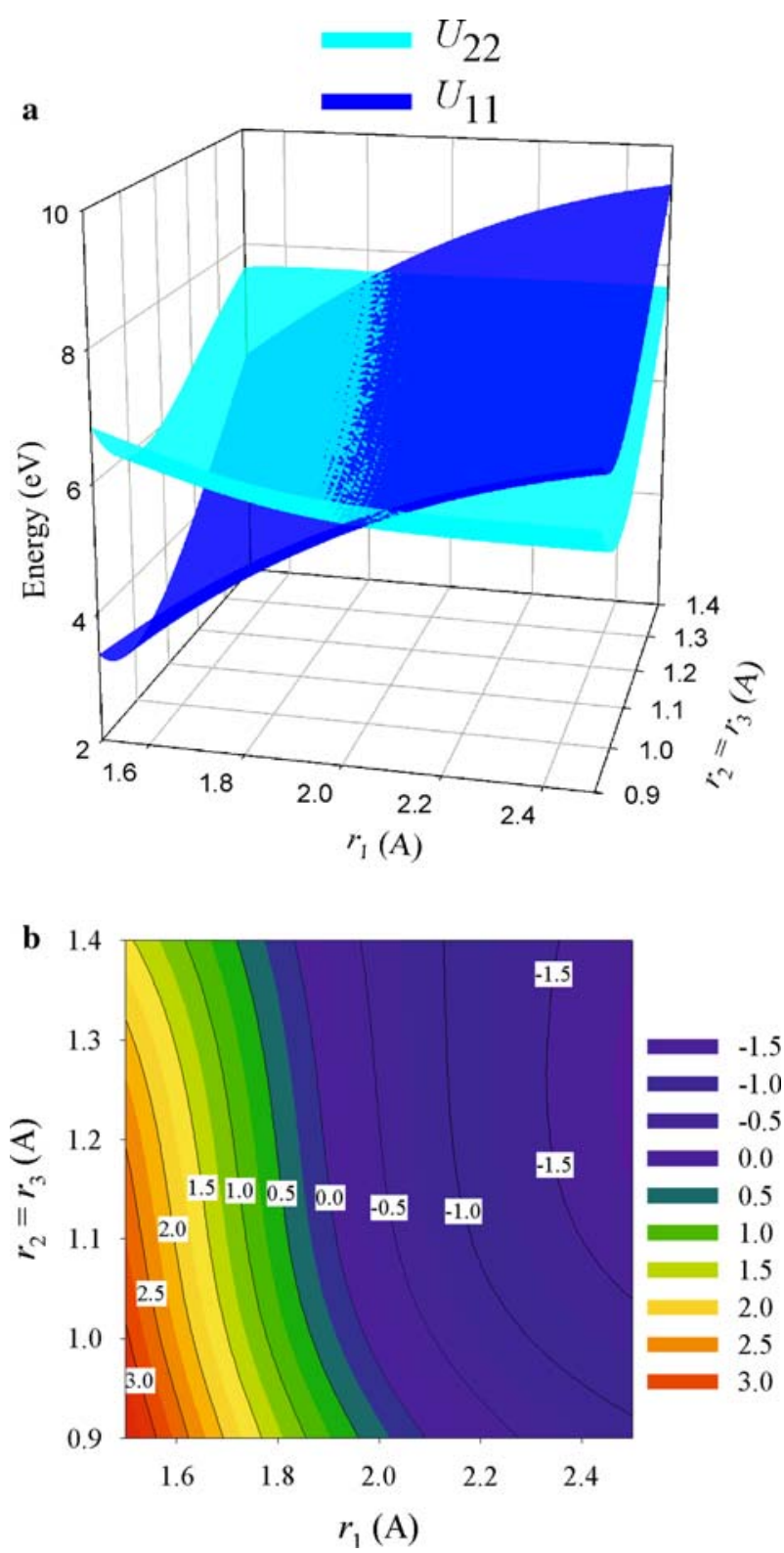

Fig. 6 a Three-dimensional plot of the $U_{11}$ and $U_{22}$ diabatic PESs and $\mathbf{b}$ the contour plot of their differences $\left(U_{22}-U_{11}\right)$ showing the diabatic crossing of the two surfaces of planar ammonia with the constraint of $C_{2 v}$ symmetry. Other geometrical parameters are allowed to relax on the $U_{22}$ PES with the constraint of $C_{2 \mathrm{v}}$ symmetry

on the $U_{22}$ surface. Actually, only one parameter, i.e., one $\mathrm{H}-\mathrm{N}-\mathrm{H}$ angle, is allowed to relax under the constraint of $C_{2 v}$ symmetry. Figure 6a shows the seam of the crossing between the $U_{11}$ and $U_{22}$ surfaces. Figure $6 \mathrm{~b}$ is a contour plot of the differences between the two diabatic energies $\left(U_{22}-U_{11}\right)$. At shorter $r_{1}, U_{22}$ is higher in energy while at longer $r_{1}, U_{22}$ becomes the ground electronic state. Since $U_{12}$ vanishes for the planar structures, and the geometries are all planar, the crossing seam between the $U_{11}$ and $U_{22}$ surfaces is the location of the conical intersections. The plots indicate that the $r_{1}$ distance of the conical intersection geometries becomes shorter if the other two $\mathrm{N}-\mathrm{H}$ distances become longer.

The photodissociation patterns of the excited $\mathrm{NH}_{3}$ $\left(\tilde{A}^{1} A_{2}^{\prime \prime}\right)$ strongly depend on the vibrational mode being excited [43]. Figure 7 shows one-dimensional cuts through the potential surfaces for slightly nonplanar geometries with a trisector angle of $77.4^{\circ}$ in both $C_{\mathrm{s}}$ and $C_{1}$ symmetries; $U_{22}$ is dashed. Figure $7 \mathrm{~b}, \mathrm{c}$ correspond to symmetrical stretching of the $\mathrm{N}-\mathrm{H}$ bonds while Fig. $7 \mathrm{~d}$ corresponds to an asymmetrical stretching of the $\mathrm{N}-\mathrm{H}$ bonds.

\section{Conclusions}

In this paper we have improved the application of the fourfold way direct diabatization scheme to ammonia. The improvements in the diabatization are:

1. We define a geometry-dependent $p$ orbital as a globally appropriate reference diabatic molecular orbital.

2. We use carefully selected dominant configuration lists that include the dominant character of the diabatic configuration state functions at a global set of geometries.

Using the diabatic energies and couplings calculated with the new diabatization scheme, we have refitted the first two diabatic potential-energy surfaces, $U_{11}$ and $U_{22}$, and their coupling, $U_{12}$, with improved functional forms and an improved fitting scheme. The improvements of the functional forms are:

1. A correction function is used to reproduce the four most important experimental energy differences exactly: (a) the dissociation energy $D_{e}$ for the dissociation of ammonia to the ground state of products; (b) the dissociation energy $D_{e}$ for the dissociation of ammonia to the excited state of products; (c) the excitation energy $T_{e}$ for $\mathrm{NH}_{3}\left(\tilde{X}^{1} A_{1}\right) \rightarrow$ $\mathrm{NH}_{3}\left(\tilde{A}^{1} A_{2}^{\prime \prime}\right)$; and (d) the excitation energy $T_{e}$ for $\mathrm{NH}_{2}\left(\tilde{X}^{2} B_{1}\right) \rightarrow \mathrm{NH}_{2}\left(\tilde{A}^{2} A_{1}\right)$.

2. We use a new function $g\left(n, \theta_{i}, r_{j}, r_{k}\right)$ for fitting the dependence on bond angle because it has better behavior for $\theta_{i}=\pi$.

3. The $U_{22}$ potential-energy surface is fitted with just one functional form, as for $U_{11}$, and the number of terms in the polynomials used in the fitting functions for both $U_{11}$ and $U_{22}$ are greatly reduced. 

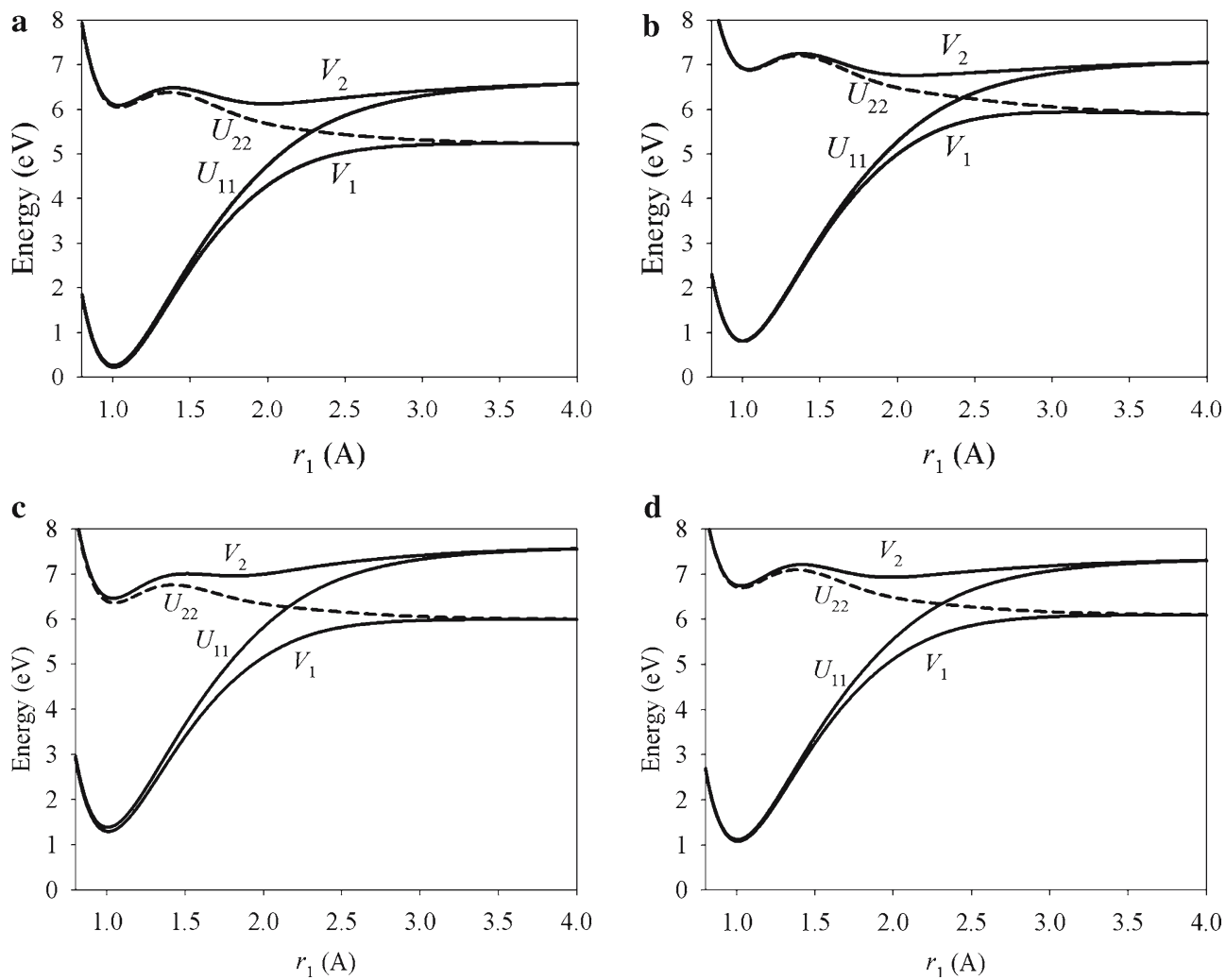

Fig. $7 V_{2}, U_{11}, U_{22}$, and $V_{1}$ versus $r_{1}$ with $\theta_{1}=120^{\circ}, \theta_{2}=\theta_{3}=113^{\circ}, \mathbf{a} r_{2}=r_{3}=1.04 \AA$, b $r_{2}=r_{3}=0.90 \AA$, $\mathbf{c} r_{2}=r_{3}=1.19 \AA$, d $r_{2}=0.90 \AA, r_{3}=1.19 \AA$

Therefore the new analytical potential can be evaluated significantly faster than the previous function.

Acknowledgments The authors are grateful to Shikha Nangia and Ahren Jasper for assistance and to Mark Gordon for permission to port the ISA algorithm from GAMESS to HONDOPLUS. This work was supported in part by the National Science Foundation through grant no. CHE03-49122.

\section{References}

1. Nangia S, Truhlar DG (2006) J Chem Phys 124:124309

2. Nakamura H, Truhlar DG (2001) J Chem Phys $115: 10353$

3. Nakamura H, Truhlar DG (2002) J Chem Phys 117:5576

4. Nakamura H, Truhlar DG (2003) J Chem Phys 118:6816

5. Atchity GJ, Ruedenberg K (1993) J Chem Phys 99:3790

6. Ruedenberg K, Atchity GJ (1993) J Chem Phys 99:3799

7. Nakano H (1993) J Chem Phys 99:7983

8. Nakano H (1993) Chem Phys Lett 207:372

9. Nakano H, Nakajima T, Tsuneda T, Hirao K (2001) J Mol Struct 573:91

10. Ruedenberg K, Sundberg R (1976) In: Calais, J-L, Goscinski O, Linderberg J, Öhrn Y (Eds) Quantum Science. Plenum, New York, p 505

11. Roos, BO (1987) Adv Chem Phys 69:399

12. Witek HA, Choe Y-K, Finley JP, Hirao K (2002) J Comput Chem 10:957

13. Krishnan R, Binkley JS, Seeger R, Pople JA (1980) J Chem Phys 72:650

14. Frisch MJ, Pople JA, Binkley JS (1984) J Chem Phys 80:3265
15. Nakamura H, Xidos JD, Chamberlin AC, Kelly CP, Valero R, Thompson JD, Li J, Hawkins GD, Zhu T, Lynch BJ, Volobuev Y, Rinaldi D, Liotard DA, Cramer CJ, Truhlar DG (2007) HONDOPLUS v5.1, based on HONDO-v99.6 University of Minnesota, Minneapolis

16. Dupuis M, Marquez A, Davidson ER (1999) HONDO 99.6, based on Dupuis M, Marquez A, Davidson ER, HONDO 95.3, Quantum Chemistry Program Exchange, Indiana University, Bloomington, IN 47405

17. Schmidt MW, Baldridge KK, Boatz JA, Elbert ST, Gordon MS, Jensen JH, Koseki S, Matsunaga N, Nguyen KA, Su SJ, Windus TL, Dupuis M, Montgomery JA (1993) J Comput Chem 14:1347

18. Frisch MJ, Trucks GW, Schlegel HB, Scuseria GE, Robb MA, Cheeseman JR, Montgomery Jr. JA, Vreven T, Kudin KN, Burant JC, Millam JM, Iyengar SS, Tomasi J, Barone V, Mennucci B, Cossi M, Scalmani G, Rega N, Petersson GA, Nakatsuji H, Hada M, Ehara M, Toyota K, Fukuda R, Hasegawa J, Ishida M, Nakajima T, Honda Y, Kitao O, Nakai H, Klene M, Li X, Knox JE, Hratchian HP, Cross JB, Bakken V, Adamo C, Jaramillo J, Gomperts R, Stratmann RE, Yazyev O, Austin AJ, Cammi R, Pomelli C, Ochterski JW, Ayala PY, Morokuma K, Voth GA, Salvador P, Dannenberg JJ, Zakrzewski VG, Dapprich S, Daniels AD, Strain MC, Farkas O, Malick DK, Rabuck AD, Raghavachari K, Foresman JB, Ortiz JV, Cui Q, Baboul AG, Clifford S, Cioslowski J, Stefanov BB, Liu G, Liashenko A, Piskorz P, Komaromi I, Martin RL, Fox DJ, Keith T, Al-Laham MA, Peng CY, Nanayakkara A, Challacombe M, Gill PMW, Johnson B, Chen W, Wong MW, Gonzalez C, Pople JA (2004) Gaussian 03, Revision D.01, Gaussian, Inc., Wallingford CT 
19. Léonard C, Handy NC, Carter S, Bowman JM (2002) Spectrochim Acta Part A 58:825

20. Landolt-Börnstein (1976) Numerical Data and Function Relationships in Science and Technology II $(7,2)$. Springer, Heidelberg. Cited in Pesonen J, Miani A, Halonen L (2001) J Chem Phys 115:1243

21. Coy SL, Lehmann KK (1989) Spectrochim Acta Part A 45:47

22. Martin JML, Lee TJ, Taylor PR (1992) J Chem Phys 97:8361

23. Handy NC, Carter S, Colwell SM (1999) Mol Phys 96:477

24. Mordaunt DH, Dixon RN, Ashfold MNR (1996) J Chem Phys 104:6472

25. Henck SA, Mason MA, Yan WB, Lehmann KK, Coy SL (1995) J Chem Phys 102:4772

26. Bach A, Hutchison JM, Holiday RJ, Crim FF (2002) J Chem Phys 116:9315

27. Morino I, Kawaguchi KJ (1997) Mol Spectrosc 182:428

28. Gabriel W, Chambaud G, Rosmus P, Carter S, Handy NC (1994) Mol Phys 81:1445

29. Jacox ME (1994) J Phys Chem Ref Data Monograph 3

30. Herzberg G (1966) Molecular Spectra and Molecular structure, vol. 3. Van Nostrand Reinhold, New York. Cited in McCarthy MI, Rosmus P, Werner H-J, Botschwina P, Vaida V (1987) J Chem Phys 86:6693

31. As reported in http://webbook.nist.gov/chemistry
32. Ruscic B, Boggs JE, Burcat A, Császár AG, Demaison J, Janoschek R, Martin JML, Morton ML, Rossi MJ, Stanton JF, Szalay PG, Westmoreland PR, Zabel F, Bérces T (2005) J Phys Chem Ref Data 34:573 and references therein

33. Hargiss LO, Ermler WC (1988) J Phys Chem 92:300

34. Gatti F, Lung C, Leforestier C, Chapuisat X (1999) J Chem Phys 111:7236

35. Demaison J, Margulès L, Boggs JE (2003) Phys Chem Chem Phys 5:3359

36. Barone V (2004) J Chem Phys 120:3059

37. Douglas AE (1963) Discuss Faraday Chem Soc 35:158

38. Dixon RA (1996) Mol Phys 88:949

39. Duchovic RJ, Volobuev YL, Lynch GC, Truhlar DG, Allison TC, Wagner F, Garrett BC, Corchado JC (2002) Comput Phys Commun 144:169

40. Duchovic RJ, Volobuev Y L, Lynch GC, Truhlar DG, Allison TC, Wagner F, Garrett BC, Corchado JC (2004) 156:319(E)

41. Duchovic RJ, Volobuev YL, Jasper AW, Lynch GC, Truhlar DG, Allison TC, Wagner F, Garrett BC, Espinosa-García J, Corchado JC POTLIB-online. http://comp.chem.umn.edu/ potlib

42. Yarkony DR (2004) J Chem Phys 121:628

43. Bach A, Hutchison JM, Holiday RJ, Crim FF (2003) J Phys Chem A 107:10490 